\title{
Broad and Region-Specific Impacts of the Synthetic Cannabinoid CP 55,940 in Adolescent and Adult Female Mouse Brains
}

\author{
Emma Leishman', Michelle N. Murphy ${ }^{1,2}$, Michelle I. Murphy 1,3,4, Ken Mackie ${ }^{1,2,3}$ and \\ Heather B. Bradshaw ${ }^{1,2 *}$ \\ ${ }^{1}$ Program in Neuroscience, Indiana University, Bloomington, IN, United States, ${ }^{2}$ Department of Psychological and Brain \\ Sciences, Indiana University, Bloomington, IN, United States, ${ }^{3}$ Gill Center for Biomolecular Science, Indiana University, \\ Bloomington, IN, United States, ${ }^{4}$ Department of Counseling and Educational Psychology, Indiana University, Bloomington, \\ IN, United States
}

\section{OPEN ACCESS}

Edited by:

Ildikó Rácz,

Universitätsklinikum Bonn, Germany

Reviewed by:

Bruno Pradier,

Brown University, United States

Laura Bindila,

Johannes Gutenberg University

Mainz, Germany

Valéria de Almeida,

Universidade Estadual de Campinas,

Brazil

*Correspondence:

Heather B. Bradshaw hbbradsh@indiana.edu

Received: 17 August 2018 Accepted: 08 November 2018 Published: 27 November 2018

Citation:

Leishman E, Murphy MN,

Murphy MI, Mackie $K$ and

Bradshaw HB (2018) Broad

and Region-Specific Impacts of the

Synthetic Cannabinoid CP 55,940

in Adolescent and Adult Female

Mouse Brains.

Front. Mol. Neurosci. 11:436.

doi: 10.3389/fnmol.2018.00436
Relative to $\Delta^{9}$-tetrahydrocannabinol (THC), the synthetic cannabinoid CP 55,940 (CP) is significantly more potent and efficacious at cannabinoid receptors, the primary targets for endogenous cannabinoids (eCBs). eCBs belong to a large, interconnected lipidome of bioactive signaling molecules with a myriad of effects in optimal and pathological function. Recreational use of highly potent and efficacious synthetic cannabinoids is common amongst adolescents, potentially impacting brain development. Knowledge of the molecular outcomes of synthetic cannabinoid use will be important to develop more targeted therapies for synthetic cannabinoid intoxication and to prevent long-term disruption to the CNS. Here, we test the hypothesis that CP has age and regiondependent effects on the brain lipidome. Adolescent [post-natal day (PND) 35 and PND 50] and young adult female mice were given either an acute dose of CP or vehicle and brains were collected $2 \mathrm{~h}$ later. Eight brain regions were dissected and levels of $\sim 80$ lipids were screened from each region using HPLC/MS/MS. CP had widespread effects on the brain lipidome in all age groups. Interestingly, more changes were observed in the PND 35 mice and more were reductions in a lipid's concentration, including regiondependent lowering of eCB levels. CP levels were highest in the cortex at PND 35, the hippocampus at PND 50, and in the cerebellum in the adult. These data provide novel insights into how high-potency, synthetic cannabinoids drive different, age-dependent, cellular signaling effects in the brain.

Keywords: lipidomics, endogenous cannabinoid, CNS, lipoamine, synthetic cannabinoid, prostaglandin

Abbreviations: 2-AG, 2-arachidonoyl glycerol; 2-LG, 2-linoleoyl glycerol; 2-PG, 2-palmitoyl glycerol; 5-LOX, 5lipoxygense; AA, arachidonic acid; ABHD12, $\alpha / \beta$-hydrolase domain 12; ABPP, activity based protein profiling; AEA, $N$-arachidonoyl ethanolamine (anandamide); A-GABA, $N$-arachidonoyl GABA; A-Phe, $N$-arachidonoyl phenylalanine; A-Ser, $N$-arachidonoyl serine; A-Taur, $N$-arachidonoyl taurine; CBD, cannabidiol; CER, cerebellum (specific to this study); CNP, 2 $2^{\prime} 3^{\prime}$-cyclic nucleotide $3^{\prime}$-phosphodiesterase; CP, CP 55,940; CTX, cortex (specific to this study); $\mathrm{d}_{8} \mathrm{NAGly}$, deuterium labeled $N$-arachidonoyl glycine; DAGL, diacylglycerol lipase; DAT, dopamine transporter; DEA, $N$-docosahexaenoyl ethanolamine; eCB, endogenous cannabinoid; HIPP, hippocampus (specific to this study); HPLC/MS/MS, high pressure liquid chromatography coupled with tandem mass spectrometry; HYP, hypothalamus (specific to this study); KO, knockout; LEA, $N$-linoleoyl ethanolamine; MID, midbrain (specific to this study); NAE, $N$-acyl ethanolamine; NAGly, $N$-arachidonoyl glycine; OEA, $N$-oleoyl ethanolamine; PEA, $N$-palmitoyl ethanolamine; PG, prostaglandin; PND, post-natal day; STEM, brainstem (specific to this study); STR, striatum (specific to this study); THAL, thalamus (specific to this study); THC, $\Delta^{9}$-tetrahydrocannabinol. 


\section{INTRODUCTION}

The cannabis plant's primary psychoactive component, THC activates the cannabinoid receptors $\mathrm{CB}_{1}$ (Devane et al., 1988) and $\mathrm{CB}_{2}$ (Munro et al., 1993), which are also targets for eCBs. With enriched expression in the brain, $\mathrm{CB}_{1}$ mediates most of the behavioral effects and abuse liability of THC (Tseng and Craft, 2004; Huestis et al., 2007). In addition to endogenous and plant-derived cannabinoids, there are synthetic cannabinoids that are typically more potent and efficacious at cannabinoid receptors (Castaneto et al., 2014; Kemp et al., 2016). One of the first synthetic cannabinoids synthesized was CP 55,940 (CP) (Uchiyama et al., 2009a). CP is a high efficacy agonist for cannabinoid receptors, whereas THC is considered a low efficacy agonist (Pertwee, 2008; Castaneto et al., 2014; Thomas, 2017). Likewise, CP has $\sim 10$-fold higher potency than THC (Showalter et al., 1996; Besnard et al., 2012). For example, CP stimulated G-protein binding at $\mathrm{CB}_{1}$ with an $\mathrm{EC}_{50}$ of $3.4 \mathrm{nM}$, whereas $\mathrm{THC}$ had an $\mathrm{EC}_{50}$ of $167.4 \mathrm{nM}$ (Brents et al., 2011). In another assay measuring functional inhibition of cAMP accumulation, $\mathrm{CP}$ was a more effective agonist at $\mathrm{CB}_{1}$ and $\mathrm{CB}_{2}$ receptors than THC. $\mathrm{CP}$ inhibited adenylate cyclase with an $\mathrm{IC}_{50}$ of $1.83 \mathrm{nM}$ at $\mathrm{CB}_{1}$ and an $\mathrm{IC}_{50}$ of $2.89 \mathrm{nM}$ at $\mathrm{CB}_{2}$, whereas THC had an $\mathrm{IC}_{50}$ of $16.5 \mathrm{nM}$ at $\mathrm{CB}_{1}$ and $41.8 \mathrm{nM}$ at $\mathrm{CB}_{2}$ (Felder et al., 1995).

Derived from AA, eCBs like AEA (Devane et al., 1992) and 2-AG (Mechoulam et al., 1995; Sugiura et al., 1995) belong to larger families of bioactive lipid signaling molecules. For example, AEA is a lipoamine, a fatty acid conjugated to an amine (Huang et al., 2001) (Supplementary Figure 1). Demonstrating effects on signaling beyond $\mathrm{CB}_{1}$, many AA-derived lipoamines, like AEA (Zygmunt et al., 1999), A-Taur (Saghatelian et al., 2006), and A-GABA are agonists at the capsaicin-sensitive TRPV1 channel (Raboune et al., 2014). NAGly is an AEA metabolite (Bradshaw et al., 2009a) that activates GPR18 and GPR55 (McHugh et al., 2010, 2012; Console-Bram et al., 2014, 2017). Using targeted screening methods, we regularly measure AEA, its lipoamine structural analogs, 2-AG, its 2-acyl glycerol structural analogs, AA-derived PGs, and free fatty acids in samples extracted from a variety of tissues, including mouse brain, and show that they belong to a wider, interconnected lipidome in the brain and throughout the body, with important roles in health and disease (Rimmerman et al., 2008; Bradshaw et al., 2009b; Smoum et al., 2010; Bradshaw and Allard, 2011; Raboune et al., 2014; Leishman et al., 2016a,b).

Previously, we demonstrated that developmental context influences acute THC's effects on the brain's lipidome. Specifically, the adult brain showed more and different changes in lipid levels $2 \mathrm{~h}$ after a single THC injection than the adolescent brain; however, the adolescent brains did show increases in PGs, whereas, the adult showed decreases (Leishman et al., 2018). Although plant-derived cannabis is the most widely used illicit drug (Miech et al., 2016), the misuse of synthetic cannabinoids, sold under brand names such as "spice" and "K2," is prevalent (Castaneto et al., 2014; Gilbert et al., 2015; Müller et al., 2015; Kemp et al., 2016; Miech et al., 2016). Some of the effects of these compounds are severe and detrimental to public health (Castaneto et al., 2014; Müller et al., 2015). There are reports of heart attacks, kidney failure, psychosis, and even deaths in people who consumed synthetic cannabinoids (Davidson et al., 2017; Moeller et al., 2017; Samra et al., 2017; Manix et al., 2018). Tragically, most of these people were young and apparently healthy (Underwood, 2015; Samra et al., 2017; Manix et al., 2018). Given unknown effects on the developing brain, the prevalence of synthetic cannabinoid use amongst teenagers and young adults is of particular concern. For example, over 6\% of high school seniors in the United States admitted to using synthetic marijuana in the past year in a 2014 survey and 2.9\% were current synthetic cannabinoid users (Miech et al., 2016). In the European Union, over 7\% of 15- to 18-year olds reported using spice or a similar drug in their lifetime (Müller et al., 2015). In animal models, the use of CP during adolescence had detrimental effects on motivated behaviors and memory in adulthood (Biscaia et al., 2003, 2008; O'Shea et al., 2004, 2006; Higuera-Matas et al., 2008, 2010; Chadwick et al., 2011; Mateos et al., 2011; Renard et al., 2013), which were often more severe in females (Biscaia et al., 2003, 2008; Higuera-Matas et al., 2008; Mateos et al., 2011). Here, we will use CP as an archetype for the many available high-affinity, synthetic cannabinoids, as they all share the commonality of being significantly more potent than THC (Castaneto et al., 2014; Fantegrossi et al., 2014; Kemp et al., 2016; Davidson et al., 2017).

Effects of CP (or any synthetic cannabinoid) on the broader lipidome have not been studied. Here, we test the hypothesis that $\mathrm{CP}$ exposure will broadly alter the brain lipidome and that these effects will be age-dependent. Providing a novel perspective of acute CP's effects on the brain, this data will add to growing evidence that drugs targeting the $\mathrm{eCB}$ system have widespread effects on bioactive lipid regulation. This knowledge may aid in our understanding of how to treat synthetic cannabinoid overdoses that have deleterious effects on brain function.

\section{MATERIALS AND METHODS}

\section{Mice, Drug Injections, and Tissue Collection}

The Bloomington Institutional Animal Care and Use Committee of Indiana University reviewed and approved the animal procedures. Female mice from the CD1 strain were utilized to match our study examining THC's effects on the brain lipidome (Leishman et al., 2018). Mice were given a single i.p. injection of either $3 \mathrm{mg} / \mathrm{kg}$ CP or 1:1:18 cremophor:ethanol:saline vehicle (please refer to the section " $3 \mathrm{mg} / \mathrm{kg}$ CP Is Relevant for Synthetic Cannabinoid Abuse and Has Stronger Effects on the Female Mouse Brain Lipidome During Adolescence" for a justification of dose and use of female mice). Three different age groups were given injections: PND 35 and PND 50 adolescents, and adult mice (PND 113). At least eight mice in each age group received $\mathrm{CP}$ and at least eight received vehicle. Matching the THC study time course (Leishman et al., 2018), mice were sacrificed via rapid decapitation $2 \mathrm{~h}$ after injection. Brains were immediately removed and flash-frozen in liquid nitrogen, and then stored at $-80^{\circ} \mathrm{C}$ until dissections were performed. 
Brains were dissected on an ice-cold dissection plate into the following regions: STR, HIPP, CER, THAL, CTX, HYP, MID, and STEM. These abbreviations for these brain areas will be used exclusively when discussing the results generated by these specific dissections. Each dissected area was immediately placed in liquid nitrogen and then stored at $-80^{\circ} \mathrm{C}$ until used for lipid extraction.

\section{Lipid Extraction and High-Pressure Liquid Chromatography Coupled to Tandem Mass Spectrometry (HPLC/MS/MS)}

Tissue extracts were performed as previously described (Bradshaw et al., 2006; Stuart et al., 2013; Raboune et al., 2014; Leishman et al., 2016a,b, 2017, 2018). First, samples were shock frozen in liquid nitrogen, weighed, and transferred to a centrifuge tube. The mass of the largest sample was multiplied by 50 to determine how many milliliters of HPLC-grade methanol (Fisher, Fair Lawn, NJ, United States) to add. Then, samples were spiked with 500 pmol deuterium-labeled NAGly ( $\mathrm{d}_{8}$ NAGly; Cayman Chemical, Ann Arbor, MI, United States). Samples were placed on ice in darkness for $2 \mathrm{~h}$ then individually homogenized and centrifuged at $19,000 \times g$ for $20 \mathrm{~min}$ at $20^{\circ} \mathrm{C}$. Supernatants were diluted with HPLC water (purified in house) to make a solution of $75 \%$ water, $25 \%$ supernatant. Lipids were partially purified on C18 solid phase extraction columns (Agilent, Palo Alto, CA, United States). A series of four elutions with $1.5 \mathrm{~mL}$ of $60 \%, 75 \%, 85 \%$, and $100 \%$ methanol were collected (Stuart et al., 2013; Leishman et al., 2016a,b, 2018).

As previously described (Bradshaw et al., 2006; Tan et al., 2006; Smoum et al., 2010; Stuart et al., 2013; Tortoriello et al., 2013; Raboune et al., 2014; Leishman et al., 2016a,b, 2017, 2018), samples were analyzed using an Applied Biosystems API 3000 triple quadrupole mass spectrometer with electrospray ionization
(Foster City, CA, United States). Using an Agilent XDB-C18 reversed phase analytical column and optimized mobile phase gradients, $20 \mu \mathrm{L}$ from each elution were chromatographed. Two Shimadzu 10ADvp pumps (Columbia, MD, United States) provided the pressure for gradient elution. Mobile phase A: $20 \%$ methanol, $80 \%$ water (v/v) and $1 \mathrm{mM}$ ammonium acetate (Sigma, St. Louis, MO, United States). Mobile phase B: 100\% methanol, $1 \mathrm{mM}$ ammonium acetate. Every method run began with $0 \%$ mobile phase B, reached $100 \%$ mobile phase B flowing at $0.2 \mathrm{~mL} / \mathrm{min}$, and gradually returned to $0 \%$ mobile phase B.

\section{Data Analysis and Statistical Procedures}

The Bradshaw lab possesses a screening library for selected lipoamines, 2-acyl glycerols, PGs, and free fatty acids, and has multiple reactions monitoring HPLC/MS/MS methods tailored for groups of structurally similar compounds to detect the $\sim 80$ lipids in the library (Supplementary Figure 2). This screening library will be referred to as the lipidome when discussing data from this study. HPLC/MS/MS data were analyzed using Analyst software (Applied Biosystems) (Bradshaw et al., 2006; Tan et al., 2006; Stuart et al., 2013; Tortoriello et al., 2013; Raboune et al., 2014; Leishman et al., 2016a,b, 2017, 2018). Chromatograms (Supplementary Figure 3) were generated by determining the retention time of analytes from the analytical column with a $[\mathrm{M}-1]$ or $[\mathrm{M}+1]$ parent peak and a fragmentation peak corresponding to the programmed values. Thus, unknown lipids are matched to known standards according to retention time and their mass fingerprint.

Extraction efficiency was calculated with the $\mathrm{d}_{8}$ NAGly spiked recovery vial as previously described (Bradshaw et al., 2006; Tan et al., 2006; Stuart et al., 2013; Tortoriello et al., 2013; Raboune et al., 2014; Leishman et al., 2016a,b, 2017, 2018). For each individual lipid in each of the areas, concentrations in moles per gram adjusted for extraction efficiency from the drug treated

\begin{tabular}{|c|c|c|c|c|c|c|}
\hline & \multicolumn{2}{|c|}{ PND 35} & \multicolumn{2}{|c|}{ PND 50} & \multicolumn{2}{|c|}{ Adult } \\
\hline & Increased & Decreased & Increased & Decreased & Increased & Decreased \\
\hline STR & $9.68 \%$ & $35.48 \%$ & $7.70 \%$ & $21.15 \%$ & $2.50 \%$ & $17.50 \%$ \\
\hline HIPP & $13.85 \%$ & $46.15 \%$ & $13.04 \%$ & $21.74 \%$ & $5.88 \%$ & $17.65 \%$ \\
\hline CER & $12.86 \%$ & $30.00 \%$ & $6.67 \%$ & $31.67 \%$ & $1.89 \%$ & $37.74 \%$ \\
\hline THAL & $21.74 \%$ & $21.74 \%$ & $3.51 \%$ & $31.58 \%$ & $9.26 \%$ & $18.52 \%$ \\
\hline CTX & $17.14 \%$ & $28.57 \%$ & $12.90 \%$ & $20.97 \%$ & $1.72 \%$ & $12.07 \%$ \\
\hline HYP & $7.84 \%$ & $41.18 \%$ & $4.08 \%$ & $4.08 \%$ & $7.89 \%$ & $10.53 \%$ \\
\hline MID & $18.06 \%$ & $25.00 \%$ & $3.23 \%$ & $38.71 \%$ & $5.55 \%$ & $18.52 \%$ \\
\hline STEM & $15.72 \%$ & $7.14 \%$ & $4.84 \%$ & $20.97 \%$ & $3.45 \%$ & $18.96 \%$ \\
\hline
\end{tabular}

FIGURE 1 | Percentage of significant changes in the CD1 female mouse brain lipidome in post-natal day (PND) 35, PND 50, and adult mice after 2-h exposure to systemic CP 55,940 (CP). The green portions of the figure represent the percentage of lipids detected in each brain area (row) that increased with acute $3 \mathrm{mg} / \mathrm{kg} \mathrm{CP}$ relative to vehicle in each age group (column) and the orange parts represent the percentage of lipids detected in each brain area (row) that decreased with acute $3 \mathrm{mg} / \mathrm{kg}$ CP relative to vehicle in each age group (column). The areas with the most changes are shaded in darker colors. STR, striatum; HIPP, hippocampus; CER, cerebellum; THAL, thalamus; CTX, cortex; HYP, hypothalamus; MID, midbrain; STEM, brainstem. For example, in the adult MID, there were 54 lipids detected and 13 of them changed with acute CP. Of the 13 changes, 3 of them were increases. 3 was then divided by the number of lipids detected, which in this case was 54 , and multiplied by 100 to yield the percentage increased (5.55\%). For the adult MID, 10 lipids decreased with acute CP out of 54 detected, giving a percentage of $18.52 \%$ for the proportion of the lipidome that decreased. 
A

\begin{tabular}{|c|c|c|c|c|c|c|c|c|c|c|c|c|}
\hline \multirow[b]{2}{*}{ Lipid Species } & \multicolumn{3}{|c|}{ Hippocampus } & \multicolumn{3}{|c|}{ Striatum } & \multicolumn{3}{|c|}{ Midbrain } & \multicolumn{3}{|c|}{ Brainstem } \\
\hline & $35 d$ & $50 d$ & Adult & $35 d$ & $50 d$ & Adult & $35 d$ & $50 d$ & Adult & $35 d$ & $50 d$ & Adult \\
\hline$N$-palmitoyl ethanolamine & $\downarrow$ & & & $\downarrow$ & & & & $\downarrow$ & $\downarrow$ & & & \\
\hline $\mathrm{N}$-stearoyl ethanolamine & & & & & & & & & $\uparrow$ & & & \\
\hline $\mathrm{N}$-oleoyl ethanolamine & $\downarrow$ & & & $\downarrow \downarrow$ & & $\downarrow \downarrow$ & $\downarrow$ & $\downarrow$ & & & & $\downarrow$ \\
\hline $\mathrm{N}$-linoleoyl ethanolamine & & $\downarrow \downarrow$ & & & & $\downarrow$ & $\uparrow$ & $\downarrow$ & & & & \\
\hline $\mathrm{N}$-arachidonoyl ethanolamine & $\downarrow$ & $\downarrow \downarrow$ & & & & $\downarrow \downarrow$ & & $\downarrow$ & $\downarrow$ & & & \\
\hline $\mathrm{N}$-docosahexaenoyl ethanolamine & $\downarrow$ & $\downarrow$ & & $\downarrow$ & & $\downarrow$ & & $\downarrow$ & & & & \\
\hline $\mathrm{N}$-arachidonoyl taurine & $\downarrow$ & $\downarrow$ & & $\downarrow$ & $\downarrow$ & & $\downarrow$ & & & $\downarrow$ & $\downarrow$ & $\downarrow$ \\
\hline 2-palmitoyl glycerol & & & & & & & & & & & $\downarrow$ & $\downarrow$ \\
\hline 2-oleoyl glycerol & $\downarrow$ & & & $\downarrow$ & & & & $\downarrow$ & $\downarrow$ & & $\downarrow$ & $\downarrow$ \\
\hline 2-linoleoyl glycerol & $\downarrow \downarrow$ & $\downarrow$ & $\downarrow$ & $\downarrow \downarrow$ & $\downarrow$ & & $\downarrow$ & $\downarrow$ & $\downarrow$ & $\downarrow$ & $\downarrow$ & $\downarrow$ \\
\hline 2-arachidonoyl glycerol & $\downarrow$ & & & $\downarrow$ & $\downarrow$ & $\downarrow$ & & & $\downarrow$ & $\downarrow$ & & $\downarrow$ \\
\hline Oleic acid & $\downarrow$ & & & & $\downarrow$ & & & $\downarrow$ & & & $\downarrow$ & $\downarrow$ \\
\hline Linoleic acid & $\downarrow$ & $\downarrow$ & & & $\downarrow$ & & & $\downarrow$ & & & $\downarrow$ & $\downarrow$ \\
\hline Arachidonic acid & $\downarrow$ & & & & $\downarrow$ & $\downarrow$ & $\downarrow$ & & $\downarrow$ & & & $\downarrow$ \\
\hline $\mathrm{PGE}_{2}$ & & $\uparrow$ & $\uparrow$ & $\uparrow$ & & & $\uparrow$ & $\downarrow$ & $\uparrow$ & $\uparrow$ & $\downarrow$ & $\downarrow$ \\
\hline $\mathrm{PGF}_{2 a}$ & $\uparrow$ & $\uparrow$ & $\uparrow$ & $\uparrow$ & $\uparrow$ & & $\uparrow$ & $\downarrow$ & & & $\downarrow$ & \\
\hline 6-ketoPGF $1 \alpha$ & $\uparrow$ & $\uparrow$ & & & BAL & BAL & $\downarrow$ & $\downarrow$ & $\uparrow$ & & $\downarrow$ & \\
\hline
\end{tabular}

B

Vehicle $\square 3 \mathrm{mg} / \mathrm{kg}$ CP 55,940
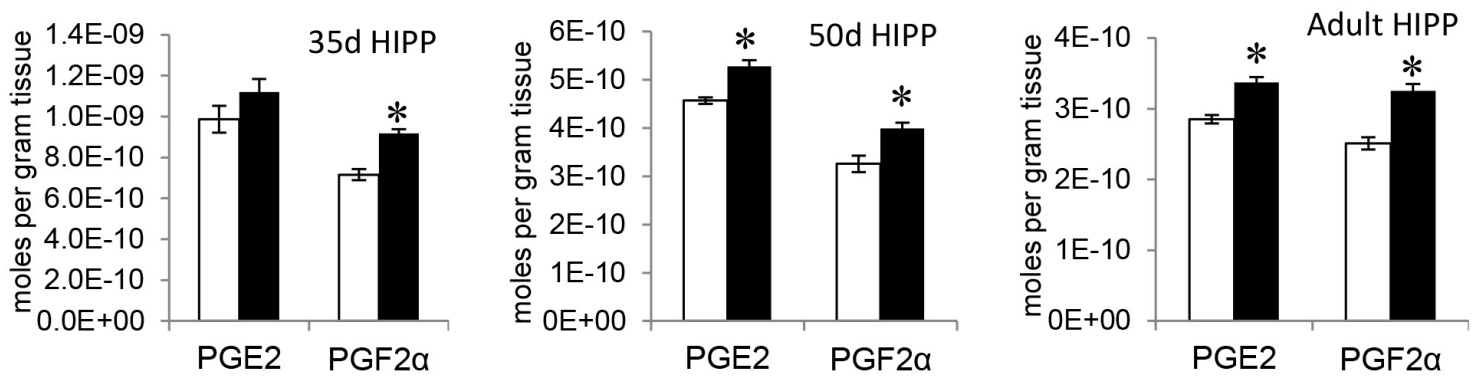

C

Vehicle $\square 3 \mathrm{mg} / \mathrm{kg}$ CP 55,940
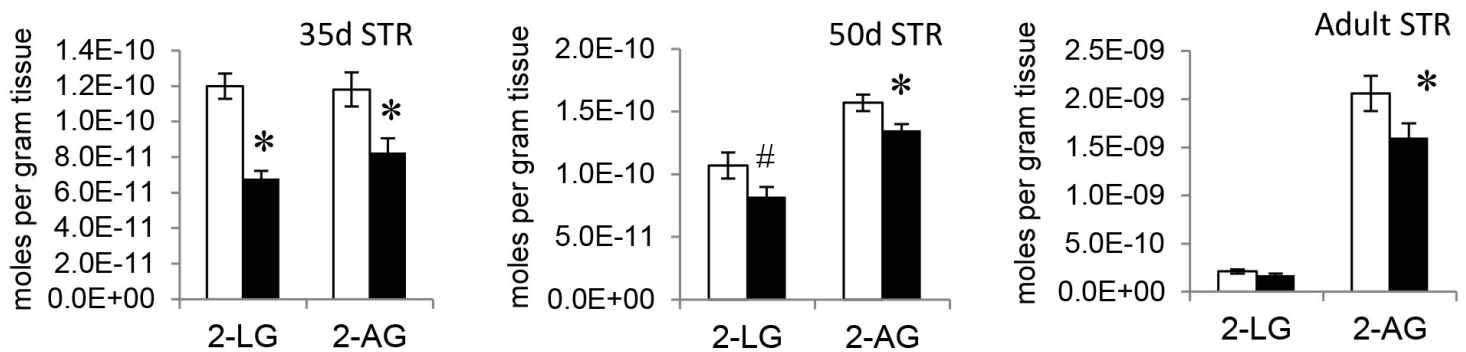

FIGURE 2 | Effects of systemic 3 mg/kg CP 55,940 (CP) on levels of targeted lipids $2 \mathrm{~h}$ after injection in the post-natal day (PND) 35, PND 50, and adult CD1 female mouse hippocampus, striatum, midbrain, and brainstem. (A) Cells with shaded arrows indicate a change for that lipid in the CP-exposed brain area relative to the same vehicle-exposed area within each age group (35d = PND 35, 50d = PND 50). The arrow color indicates the direction of a significant result relative to control. Green colors represent increases, with darker green representing a significant increase of $p<0.05$ and lighter green representing a trending increase of $p<0.10$. Orange colors represent decreases in a lipid's concentration, with darker orange indicating a significant decrease of $p<0.05$ and light orange representing a trending decrease of $p<0.10$. The number of arrows indicates the magnitude of the difference between CP and vehicle. One arrow indicates a magnitude difference of less than 1.5-fold and two arrows indicate a 1.5- to 1.99-fold change. BAL stands for "Below Analytical Limit," whereas a blank cell indicates that there was no change in the lipid's level due to CP. See Supplementary Figure $\mathbf{4}$ for a more detailed description of analysis. (B) Bar graphs showing mean levels of prostaglandin $\mathrm{E}_{2}$ (PGE 2 ) and prostaglandin $\mathrm{F}_{2 \alpha}\left(\mathrm{PGF}_{2 \alpha}\right)$ in the post-natal day 35 hippocampus (35d HIPP), post-natal day 50 hippocampus (50d HIPP), and adult hippocampus (adult HIPP) $2 \mathrm{~h}$ after a systemic vehicle injection (open bars) or a systemic $3 \mathrm{mg} / \mathrm{kg} \mathrm{CP}$ injection (black bars). The units on the $y$-axis are moles of lipid per gram of tissue.

(Continued) 


\section{FIGURE 2 | Continued}

Error bars are \pm standard error. An asterisk $\left(^{*}\right)$ represents a difference of $p<0.05$ between CP and vehicle groups. Levels of both these prostaglandins were higher in the 50d HIPP and adult HIPP (corresponding to green cells with one up arrow in panel A). In the 35d HIPP, levels of PGF $2 \alpha$ increased with CP treatment but levels of PGE 2 did not change. (C) Bar graphs showing mean levels of 2-linoleoyl glycerol (2-LG) and 2-arachidonoyl glycerol (2-AG) in the post-natal day 35 striatum (35d STR), post-natal day 50 striatum (50d STR), and adult striatum (adult STR) 2 h after a systemic vehicle injection (open bars) or a systemic 3 mg/kg CP injection (black bars). The units on the $y$-axis are moles of lipid per gram of tissue. Error bars are \pm standard error. Asterisk (*) represents a difference of $p<0.05$ between $\mathrm{CP}$ and vehicle groups and the pound sign (\#) represents a trending difference of $p<0.10$. In the 35d STR, 2-LG levels were lower in the CP-treated group (corresponding to a darker orange cell with two down arrows in panel A), whereas there was a smaller trending reduction in 2-LG in the 50d STR (corresponding to a lighter orange cell with one down arrow in panel A). No significant differences between groups in levels of 2-LG were found in the CP-treated adult STR. In all three age groups, levels of 2-AG were lower in the CP-exposed striatum (corresponding to darker orange cells with one down arrow in panel $\mathbf{A}$ ).

animals were compared to vehicle concentrations. As previously described (Leishman et al., 2016a,b), lipids with a high-degree of structural homology were grouped together and analyzed as a unit (e.g., NAEs) and analyzed using a one-way ANOVA with post hoc Fishers LSD. All statistical tests were carried out using SPSS (IBM, Armonk, NY, United States). Statistical significance was defined as $p<0.05$ and trending at $p<0.10$. Because experiments on different age groups were conducted several months apart, mean lipid levels could not be directly compared between age groups; instead, analyzed data are represented in tabular format illustrating both the direction and magnitude of change in lipid levels between CP and vehicle within an age group (key and explanation of calculations found in Supplementary Figure 4).

\section{RESULTS}

\section{Overall Effects of Acute CP on the CD1 Female Mouse Brain Lipidome}

Visual observation of the PND 35, PND 50 and the adult mice given $\mathrm{CP}$ revealed profoundly reduced locomotor activity but no mortality. Of the 73 lipoamines in our screening library (Supplementary Figure 2), over 50 were detected in most brain regions in both the vehicle and CP-treated mice at each developmental time point. Of the lipids in the library, most were detected in larger brain regions such as the CTX and $\mathrm{CER}$, and the fewest were detected in smaller regions like the HYP and STR. Each of the NAE, free fatty acid, and 2-acyl glycerol species analyzed were detected in all brain regions. There were 656 total discrete measures in endogenous lipids that could have been detected in each group (82 lipids in eight brain regions). 529 were detected in the PND 35 brain, 450 were detected in the PND 50 brain, and 406 were detected in the adult brain. The percentage of those modified with acute CP differed as a function of age wherein $43.67 \%$ of the lipids detected changed in the PND 35 brains, 31.33\% in the PND 50 brains, and $23.89 \%$ in the adult brains (Supplementary Figures 5-7). As an example calculation, levels of 8 lipids changed in the adult STR, 12 in the HIPP, 21 in the CER, 15 in the THAL, 8 in the CTX, 7 in the HYP, 13 in the MID, and 13 in the STEM (Supplementary Figure 7). Summing those gives 97. 97 divided by 406 (number of lipids detected) and multiplied by 100 gives $23.89 \%$. Full lists of analyte levels in each of the brain regions and the statistical analyses are available in Supplementary Tables 1-48.

\section{Effects on CNS Lipid Levels by CP in PND 35}

In the PND 35 mice, most (152) of the 231 total changes in lipid levels across the eight regions were decreases; however, effects were region dependent. The HIPP had the most changes with 39 lipids changed out of 65 detected, whereas, the STEM had the fewest with 16 changes out of 70 detected. The STEM was the only brain area where most of changes were increases. The PND 35 mouse brain displayed changes common to all eight brain areas, including decreases in A-GABA and A-Taur and increases in $N$-palmitoyl leucine (Figure 1 and Supplementary Figure 5).

\section{Effects on CNS Lipid Levels by CP in PND 50}

Like in the PND 35 mice, most (110) of the 141 total changes in lipid levels in PND 50 mice were decreases. The MID was the most affected region of the PND 50 brain, with 26 total changes in lipid levels out of 62 detected. However, only two of these changes were decreases. In PND 50 mice, the HYP had the fewest changes, with only four lipids changing out of 49 detected (Figure 1 and Supplementary Figure 6).

\section{Effects on CNS Lipid Levels by CP in the Adult}

In the adult brain there were fewer changes in the lipidome compared to PND 35 and PND 50. Again, most (78) of the 97 changes in lipid levels were decreases. The region most affected in the adult brain was the CER, where levels of 21 different lipids were altered (20 decreases, 1 increase) out of 53 detected. In contrast, the CTX was the least affected brain region in the adult with only eight lipids changed out of 58 (Figure 1 and Supplementary Figure 7).

\section{Acute CP Modifies Lipid Levels Across the Brain in an Age-Dependent Fashion Effects of Acute CP on Levels of Prostaglandins (PGs)}

Prostaglandins are a family of lipids with relatively wellunderstood receptors, biosynthesis, and metabolism (Funk, 2001). 15 changes (10 increases, 5 decreases) in PG levels were measured in the PND 35 brain, 5 for each PG screened. Apart from a decrease in $\mathrm{PGE}_{2}$ in the HYP, all changes in $\mathrm{PGF}_{2 \alpha}$ and $\mathrm{PGE}_{2}$ were increases. In contrast, changes in 6-keto $\mathrm{PGF}_{1 \alpha}$ were decreases except for an increase in the HIPP. The only brain area where all three PGs changed was the MID (Figures 2A,B, 3A and Supplementary Figure 5). With 7 increases and 11 decreases, most of the changes in PGs in the PND 50 brain were decreases, unlike the PND 35 brain. All 3 PGs differed in the HIPP, CER, THAL, MID, and STEM. In the HIPP, these 
A

\begin{tabular}{|c|c|c|c|c|c|c|c|c|c|c|c|c|}
\hline \multirow[b]{2}{*}{ Lipid Species } & \multicolumn{3}{|c|}{ Cerebellum } & \multicolumn{3}{|c|}{ Cortex } & \multicolumn{3}{|c|}{ Thalamus } & \multicolumn{3}{|c|}{ Hypothalamus } \\
\hline & $35 d$ & $50 d$ & Adult & $35 d$ & $50 d$ & Adult & $35 d$ & $50 d$ & Adult & $35 d$ & $50 d$ & Adult \\
\hline$N$-palmitoyl ethanolamine & & & & & & & & & $\downarrow$ & $\downarrow \downarrow$ & & \\
\hline$N$-stearoyl ethanolamine & & & & & & & & & & $\downarrow$ & & \\
\hline$N$-oleoyl ethanolamine & $\downarrow$ & $\downarrow$ & & & $\downarrow \downarrow$ & & & & $\downarrow$ & $\downarrow \downarrow$ & & \\
\hline N-linoleoyl ethanolamine & & $\downarrow$ & $\downarrow \downarrow$ & & $\downarrow$ & & $\uparrow$ & & & & & \\
\hline$N$-arachidonoyl ethanolamine & & $\downarrow$ & $\downarrow \downarrow$ & & $\downarrow$ & & $\uparrow$ & $\downarrow$ & $\downarrow$ & $\downarrow$ & & \\
\hline N-docosahexaenoyl ethanolamine & & & $\downarrow$ & & $\downarrow$ & & & & & $\downarrow \downarrow$ & & \\
\hline$N$-arachidonoyl taurine & $\downarrow$ & $\downarrow$ & $\downarrow$ & $\downarrow$ & $\downarrow$ & $\downarrow$ & $\downarrow$ & $\downarrow$ & & $\downarrow$ & & $\uparrow$ \\
\hline 2-palmitoyl glycerol & & $\downarrow$ & & $\uparrow \uparrow$ & & & & & & $\uparrow$ & & \\
\hline 2-oleoyl glycerol & & $\downarrow$ & $\downarrow$ & & $\downarrow$ & & & $\downarrow$ & & $\downarrow \downarrow$ & & \\
\hline 2-linoleoyl glycerol & $\downarrow$ & $\downarrow \downarrow$ & $\downarrow \downarrow$ & & $\downarrow$ & $\downarrow$ & $\downarrow$ & $\downarrow$ & $\downarrow$ & $\downarrow \downarrow$ & & \\
\hline 2-arachidonoyl glycerol & $\downarrow$ & & $\downarrow$ & & & & & $\downarrow$ & $\downarrow$ & $\downarrow \downarrow \downarrow$ & $\downarrow$ & \\
\hline Oleic acid & & $\downarrow$ & $\downarrow \downarrow$ & & & & & $\downarrow$ & $\downarrow$ & $\downarrow$ & & \\
\hline Linoleic acid & & $\downarrow$ & $\downarrow \downarrow$ & & $\downarrow \downarrow$ & & & $\downarrow$ & & $\downarrow$ & & \\
\hline Arachidonic acid & $\downarrow$ & $\downarrow$ & $\downarrow$ & & $\downarrow$ & $\downarrow$ & & $\downarrow$ & $\downarrow$ & $\downarrow$ & & \\
\hline $\mathrm{PGE}_{2}$ & & $\downarrow$ & $\downarrow$ & & $\downarrow$ & & $\uparrow$ & $\downarrow$ & & $\downarrow$ & & $\uparrow$ \\
\hline $\mathrm{PGF}_{2 \alpha}$ & & $\downarrow$ & $\downarrow$ & $\uparrow$ & & $\downarrow$ & & $\downarrow$ & & $\uparrow$ & $\uparrow$ & $\downarrow$ \\
\hline 6-ketoPGF ${ }_{1 \alpha}$ & $\downarrow \downarrow$ & $\uparrow$ & $\downarrow$ & $\downarrow$ & & $\downarrow$ & $\downarrow$ & $\uparrow \uparrow$ & $\uparrow$ & & & $\downarrow \downarrow$ \\
\hline
\end{tabular}

B

Vehicle $\square 3 \mathrm{mg} / \mathrm{kg}$ CP 55,940
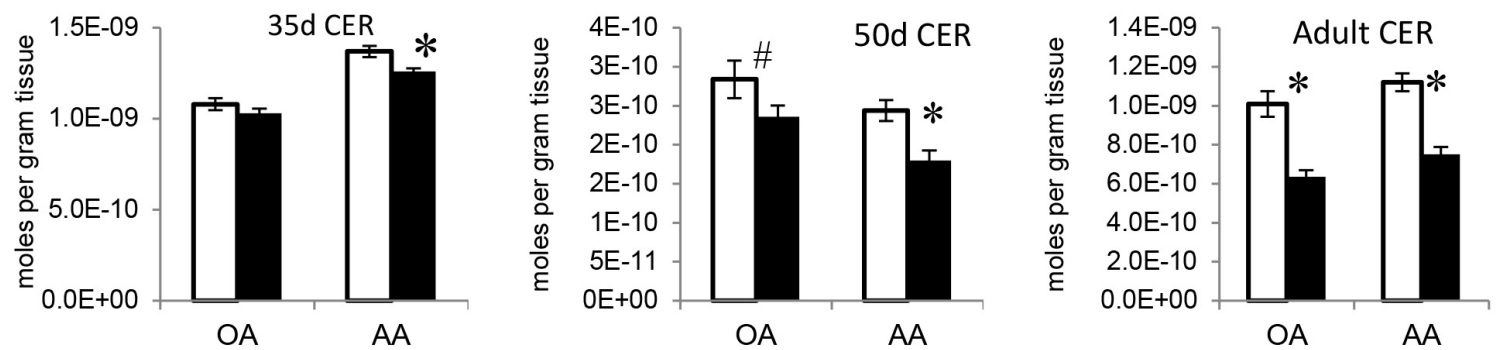

Vehicle

$3 \mathrm{mg} / \mathrm{kg}$ CP 55,940

C
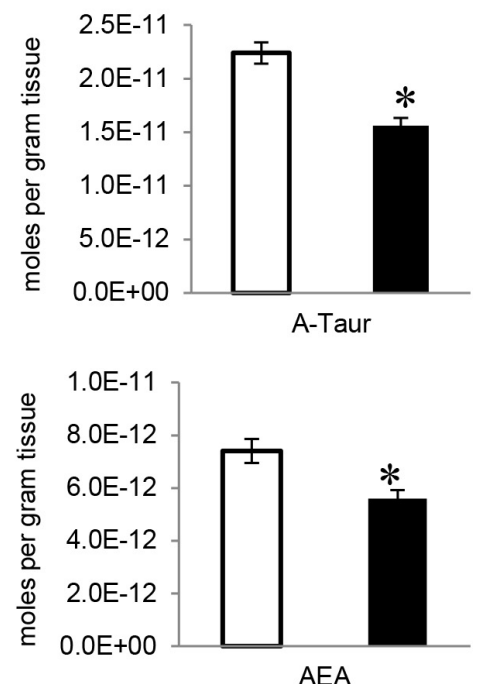

50d HYP

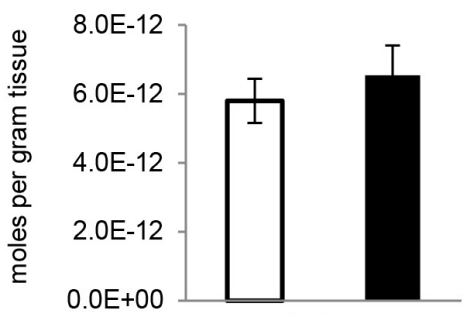

A-Taur

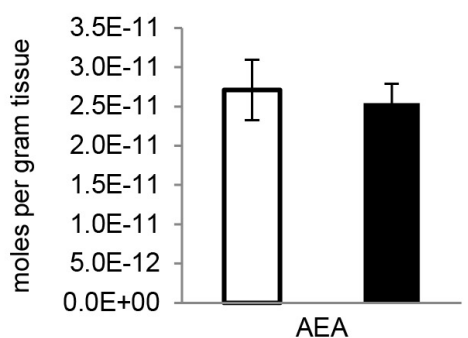

Adult HYP

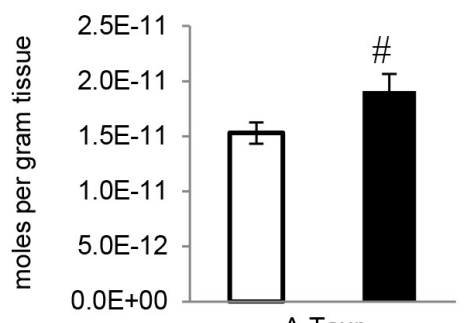

A-Taur

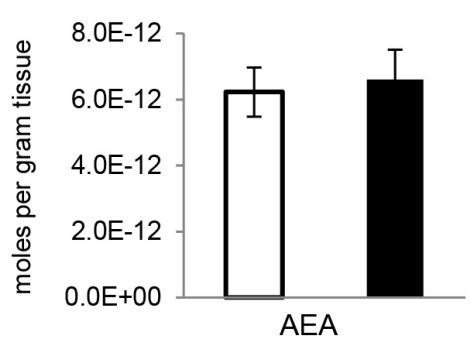

FIGURE 3 | Effects of systemic 3 mg/kg CP 55,940 (CP) on levels of targeted lipids $2 \mathrm{~h}$ after injection in the post-natal day (PND) 35, PND 50, and adult CD1 female mouse cerebellum, cortex, thalamus, and hypothalamus. (A) Cells with shaded arrows indicate a change for that lipid in the CP-exposed brain area relative to the same vehicle-exposed area within each age group (35d = PND 35, 50d = PND 50). The arrow color indicates the direction of a significant result relative to control. Green colors represent increases, with darker green representing a significant increase of $p<0.05$ and lighter green representing a trending increase of $p<0.10$. Orange colors represent decreases in a lipid's concentration, with darker orange indicating a significant decrease of $p<0.05$ and light orange representing a trending decrease of $p<0.10$. The number of arrows indicates the magnitude of the difference between CP and vehicle. 


\section{FIGURE 3 | Continued}

One arrow indicates a magnitude difference of less than 1.5-fold, two arrows indicate a 1.5- to 1.99-fold change, and three arrows indicate a 2- to 2.99-fold change. A blank cell indicates that there was no change in the lipid's level due to CP. See Supplementary Figure $\mathbf{4}$ for more detailed description of analysis. (B) Bar graphs showing mean levels of oleic acid (OA) and arachidonic acid (AA) in the post-natal day 35 cerebellum (35d CER), post-natal day 50 cerebellum (50d CER), and adult cerebellum (adult CER) $2 \mathrm{~h}$ after a systemic vehicle injection (open bars) or a systemic $3 \mathrm{mg} / \mathrm{kg}$ CP injection (black bars). The units on the $y$-axis are moles of lipid per gram of tissue. Error bars are \pm standard error. Asterisk (*) represents a difference of $p<0.05$ between CP and vehicle groups and the pound sign (\#) represents a trending difference of $p<0.10$. In the 35d CER, there was no change in levels of OA. In the 50d CER, there was a trending decrease in OA (corresponding to a lighter orange cell with one down arrow in panel $\mathbf{A}$ ), whereas there was an even larger decrease in OA in the adult CER (corresponding to an orange cell with two down arrows in panel A). In all three age groups, there was a reduction in AA levels in the CP-exposed cerebellum $2 \mathrm{~h}$ post-injection. (C) Bar graphs showing mean levels of $\mathrm{N}$-arachidonoyl taurine (A-Taur) and $\mathrm{N}$-arachidonoyl ethanolamine (AEA) in the post-natal day 35 hypothalamus (35d HYP), post-natal day 50 hypothalamus (50d HYP), and adult hypothalamus (adult HYP) $2 \mathrm{~h}$ after a systemic vehicle injection (open bars) or a systemic $3 \mathrm{mg} / \mathrm{kg} \mathrm{CP}$ injection (black bars). The units on the $y$-axis are moles of lipid per gram of tissue. Error bars are \pm standard error. Asterisk $\left(^{*}\right)$ represents a difference of $p<0.05$ between CP and vehicle groups and the pound sign (\#) represents a trending difference of $p<0.10$. In the 35d HYP, acute CP lowered levels of both A-Taur and AEA (corresponding to orange cells with one down arrow in panel A). In the 50d HYP, there are no significant differences in A-Taur or AEA levels between groups. Levels of A-Taur were trending higher in the CP-exposed adult HYP (corresponding to a lighter green cell with one up arrow in panel $\mathbf{A}$ ), but AEA levels were unaffected in this age group.

changes were increases, whereas, in the MID and STEM, they were decreases (Figures 2A,B, 3A and Supplementary Figure 6). 14 changes ( 6 increases and 8 decreases) in PG levels were found in the adult brain. Levels of all three PGs changed in the adult CER and HYP (Figures 2A, 3A and Supplementary Figure 7). The only change in PGs common to all three age groups was an increase in $\mathrm{PGF}_{2 \alpha}$ in the HIPP (Figure 2B).

\section{Effects of Acute CP on Levels of 2-Acyl Glycerols}

2-AG, 2-PG, 2-oleoyl glycerol, and 2-LG are all 2-acyl glycerols (Jung et al., 2007). Concentrations of 2-acyl glycerols typically decreased in a region-specific manner, with the exception of increases in 2-PG in the PND 35 CTX and HYP. The other 15 changes in PND 35 mice were decreases. The HYP was the only region where all four 2-acyl glycerols changed. The 2-acyl glycerol most affected was 2-LG, which decreased in every area except the CTX. Five areas had decreases in levels of 2-AG: STR, HIPP, CER, HYP, and STEM (Figures 2A,C, 3A and Supplementary Figure 5). In PND 50 mice, there were 17 decreases in 2-acyl glycerol levels. 2-LG decreased in all brain areas except the HYP. There were three regions with decreases in 2-AG: the STR, HYP, and THAL (Figures 2A,C, 3A and Supplementary Figure 6). 15 reductions were uncovered in the adult brain. In the STEM, levels of all four 2-acyl glycerols decreased. 2-LG was also the most affected 2-acyl glycerol, decreasing in six brain areas. However, levels of 2-LG did not change in the STR or HYP. 2-AG decreased in the STR, CER, THAL, MID, and STEM (Figures 2A,C, 3A and Supplementary Figure 7). The decrease in 2-AG was common to all three age groups in the STR, and, in all three age groups, 2-LG was the most affected 2-acyl glycerol measured (Figure 2C).

\section{Effects of Acute CP on Levels of Free Fatty Acids}

All changes in free fatty acid levels were decreases, regardless of age group. Eight decreases were measured in the PND 35 brain. AA had more changes than linoleic or oleic acid. Levels of all three free fatty acids decreased in the HIPP and HYP, whereas no changes occurred in the STR, THAL, CTX, and STEM (Figures 2A, 3A,B and Supplementary Figure 5). With 16 decreases, the PND 50 brain had more changes in free fatty acids. Levels of all three fatty acids decreased in the STR, CER, and THAL. Linoleic acid was the most affected free fatty acid, decreasing in every region except the HYP (Figures 2A, 3A,B and Supplementary Figure 6). In the adult mice, there were 11 decreases. All three fatty acids decreased in the CER and STEM, which were the only areas where linoleic acid levels changed. The fatty acid most affected was AA, decreasing in the STR, CER, THAL, CTX, MID, and STEM (Figures 2A, 3A,B and Supplementary Figure 7). The decrease in AA in the CER was the only change common to all age groups (Figure 3B).

\section{Effects of Acute CP on Levels of $N$-Acyl Ethanolamines}

In the PND 35 brain, there were 17 changes in NAEs. The HYP had the most changes, with decreases in PEA, $N$-stearoyl ethanolamine, OEA, AEA, and DEA. The NAE most affected was OEA, decreasing in the STR, HIPP, CER, HYP, and MID. Levels of AEA decreased in the PND 35 HIPP and HYP but increased in the THAL and were unchanged in the STR, CER, CTX, MID, and STEM (Figures 2A, 3A,C and Supplementary Figure 5). In the PND 50 brain, all 16 changes in NAEs were decreases. With decreases in five NAEs (PEA, OEA, LEA, AEA, and DEA), the MID was the most affected brain area. AEA was the most altered NAE, decreasing in the HIPP, CER, THAL, CTX, and MID (Figures 2A, 3A,C and Supplementary Figure 6). For the adult brain, there were 15 alterations in NAEs, but none were found in the HIPP, CTX, and HYP. The area with the most changes in NAEs was the STR, with significant reductions in OEA, LEA, AEA, and DEA. AEA was the most affected NAE, decreasing in the STR, CER, THAL, and MID (Figures 2A, 3A,C and Supplementary Figure 7). None of the effects on NAE levels were measured in all three age groups, illustrating the importance of developmental context.

\section{Effect of Acute $3 \mathrm{mg} / \mathrm{kg}$ CP on Levels of Lipoamines Derived From Arachidonic Acid}

Like the changes in AA itself, most changes in AA-derived lipoamines were decreases. Some of these decreases were common to all three age groups: $N$-arachidonoyl alanine in the HIPP, A-GABA in the CER and THAL, NAGly in the HIPP and THAL, and A-Taur in the CER, CTX, and STEM (Figure 4). With 50 differences, the PND 35 brain had the most changes in lipoamines derived from AA. Only two of these changes were 


\begin{tabular}{|c|c|c|c|c|c|c|c|c|}
\hline \multicolumn{9}{|c|}{ PND 35} \\
\hline Arachidonic acid and derived lipoamines & STR & HIPP & CER & THAL & CTX & HYP & MID & STEM \\
\hline Arachidonic acid & & $\downarrow$ & $\downarrow$ & & & $\downarrow$ & $\downarrow$ & \\
\hline $\mathrm{N}$-arachidonoyl alanine & $\downarrow$ & $\downarrow$ & $\downarrow$ & $\bar{\downarrow}$ & $\bar{\downarrow}$ & $\downarrow \downarrow$ & $\downarrow$ & \\
\hline $\mathrm{N}$-arachidonoyl ethanolamine & & $\downarrow$ & & $\uparrow$ & & $\downarrow$ & & \\
\hline $\mathrm{N}$-arachidonoyl GABA & $\downarrow \downarrow$ & $\downarrow \downarrow$ & $\downarrow$ & $\downarrow$ & $\downarrow$ & $\downarrow$ & $\downarrow$ & $\downarrow$ \\
\hline $\mathrm{N}$-arachidonoyl glycine & $\downarrow$ & $\downarrow$ & $\downarrow$ & $\downarrow$ & $\downarrow$ & $\downarrow$ & $\downarrow$ & \\
\hline $\mathrm{N}$-arachidonoyl methionine & BAL & BAL & $\downarrow \downarrow$ & BAL & $\downarrow \downarrow$ & BAL & & \\
\hline $\mathrm{N}$-arachidonoyl phenylalanine & $\downarrow$ & $\downarrow$ & & $\uparrow$ & $\downarrow$ & $\downarrow$ & & \\
\hline $\mathrm{N}$-arachidonoyl serine & $\downarrow \downarrow$ & $\downarrow \downarrow \downarrow$ & $\downarrow$ & $\downarrow$ & $\downarrow$ & BAL & $\downarrow$ & \\
\hline $\mathrm{N}$-arachidonoyl taurine & $\downarrow$ & $\downarrow$ & $\downarrow$ & $\downarrow$ & $\downarrow$ & $\downarrow$ & $\downarrow$ & $\downarrow$ \\
\hline $\mathrm{N}$-arachidonoyl tyrosine & $\downarrow$ & & $\downarrow$ & & $\downarrow$ & BAL & $\downarrow$ & \\
\hline \multicolumn{9}{|c|}{ PND 50} \\
\hline Arachidonic acid and derived lipoamines & STR & HIPP & CER & THAL & CTX & HYP & MID & STEM \\
\hline Arachidonic acid & $\downarrow$ & & $\downarrow$ & $\downarrow$ & $\downarrow$ & & & \\
\hline $\mathrm{N}$-arachidonoyl alanine & BAL & $\downarrow$ & BAL & BAL & $\downarrow$ & BAL & $\downarrow \downarrow$ & \\
\hline $\mathrm{N}$-arachidonoyl ethanolamine & & $\downarrow \downarrow$ & $\downarrow$ & $\downarrow$ & $\downarrow$ & & $\downarrow$ & \\
\hline $\mathrm{N}$-arachidonoyl GABA & $\downarrow$ & & $\downarrow$ & $\downarrow$ & $\downarrow$ & & $\downarrow$ & $\downarrow$ \\
\hline $\mathrm{N}$-arachidonoyl glycine & $\downarrow \downarrow$ & $\downarrow \downarrow$ & $\downarrow$ & $\downarrow \downarrow$ & & & $\downarrow \downarrow$ & \\
\hline $\mathrm{N}$-arachidonoyl methionine & BAL & BAL & BAL & BAL & BAL & BAL & $\downarrow \downarrow$ & BAL \\
\hline $\mathrm{N}$-arachidonoyl phenylalanine & $\downarrow$ & BAL & $\downarrow \downarrow$ & $\downarrow \downarrow$ & $\downarrow$ & $\downarrow$ & $\downarrow$ & $\uparrow$ \\
\hline $\mathrm{N}$-arachidonoyl serine & BAL & $\downarrow \downarrow$ & $\downarrow$ & & & BAL & & $\downarrow$ \\
\hline $\mathrm{N}$-arachidonoyl taurine & $\downarrow$ & $\downarrow$ & $\downarrow$ & $\downarrow$ & $\downarrow$ & & & $\downarrow$ \\
\hline $\mathrm{N}$-arachidonoyl tyrosine & BAL & $\uparrow$ & $\downarrow$ & $\downarrow$ & & BAL & $\downarrow$ & $\downarrow$ \\
\hline \multicolumn{9}{|c|}{ Adult } \\
\hline Arachidonic acid and derived lipoamines & STR & HIPP & CER & THAL & CTX & HYP & MID & STEM \\
\hline Arachidonic acid & $\downarrow$ & & $\downarrow$ & $\downarrow$ & $\downarrow$ & & $\downarrow$ & $\downarrow$ \\
\hline $\mathrm{N}$-arachidonoyl alanine & & $\downarrow$ & BAL & $\downarrow \downarrow$ & & BAL & & \\
\hline $\mathrm{N}$-arachidonoyl ethanolamine & $\downarrow \downarrow$ & & $\downarrow \downarrow$ & $\downarrow$ & & & $\downarrow$ & \\
\hline $\mathrm{N}$-arachidonoyl GABA & & $\downarrow$ & $\downarrow \downarrow$ & $\downarrow$ & & $\downarrow$ & & \\
\hline $\mathrm{N}$-arachidonoyl glycine & & $\downarrow$ & & $\downarrow \downarrow$ & & & & \\
\hline $\mathrm{N}$-arachidonoyl methionine & BAL & BAL & BAL & BAL & BAL & BAL & BAL & BAL \\
\hline $\mathrm{N}$-arachidonoyl phenylalanine & & $\downarrow \downarrow$ & $\overline{\downarrow \downarrow \downarrow}$ & & & & & \\
\hline $\mathrm{N}$-arachidonoyl serine & BAL & BAL & BAL & BAL & BAL & BAL & $\downarrow \downarrow$ & BAL \\
\hline $\mathrm{N}$-arachidonoyl taurine & & & $\downarrow$ & & $\downarrow$ & $\uparrow$ & & $\downarrow$ \\
\hline $\mathrm{N}$-arachidonoyl tyrosine & BAL & BAL & BAL & & & BAL & & $\downarrow \downarrow$ \\
\hline
\end{tabular}

FIGURE 4 | Effects of acute CP 55,940 (CP) on levels of arachidonic acid and arachidonic acid-derived lipoamines in eight regions of the post-natal day (PND) 35, PND 50, and adult female mouse brain. Effects in the PND 35 brain are shown in the top portion, the PND 50 effects are shown in the middle portion, and the effects in the adult brain are shown in the bottom portion of the figure. Cells with shaded arrows indicate a change for that lipid in the CP-exposed brain area relative to the same vehicle-exposed area within each age group. The arrow color indicates the direction of a significant result relative to control. Green colors represent increases, with darker green representing a significant increase of $p<0.05$ and lighter green representing a trending increase of $p<0.10$. Orange colors represent decreases in a lipid's concentration, with darker orange indicating a significant decrease of $p<0.05$ and light orange representing a trending decrease of $p<0.10$. The number of arrows indicates the magnitude of the difference between CP and vehicle. One arrow indicates a magnitude difference of less than 1.5-fold, two arrows indicates a 1.5- to 1.99-fold change, and three arrows indicate a 2- to 2.99-fold change. BAL stands for "Below Analytical Limit," whereas a blank cell indicates that there was no change in the lipid's level due to CP. See Supplementary Figure $\mathbf{4}$ for more detailed description of analysis. Abbreviations for brain areas are: STR, striatum; HIPP, hippocampus; CER, cerebellum; THAL, thalamus; CTX, cortex; HYP, hypothalamus; MID, midbrain; STEM, brainstem.

increases. These were restricted to the THAL, where levels of AEA and A-Phe increased. A-GABA and A-Taur decreased across all eight brain areas (Figure 4). Compared to the PND 35 brain, fewer changes occurred in the PND 50 brain (41 changes). A-Phe increased in the STEM and $\mathrm{N}$-arachidonoyl tyrosine increased in the HIPP, which were the only detected increases. A-Phe was the most affected AA-derived lipoamine, as levels decreased in seven of eight brain areas. The next most affected were A-GABA and A-Taur. A-GABA decreased in the STR, CER, THAL, CTX, MID, and STEM, and A-Taur decreased in the STR, HIPP, CER, THAL, CTX, and STEM (Figure 4). The adult mice had fewer changes in levels of AA-derived lipoamines (20 changes). The only increase was a modest increase in A-Taur in the HYP. With changes in four brain areas, the AA-derived lipoamines most affected were AEA, 


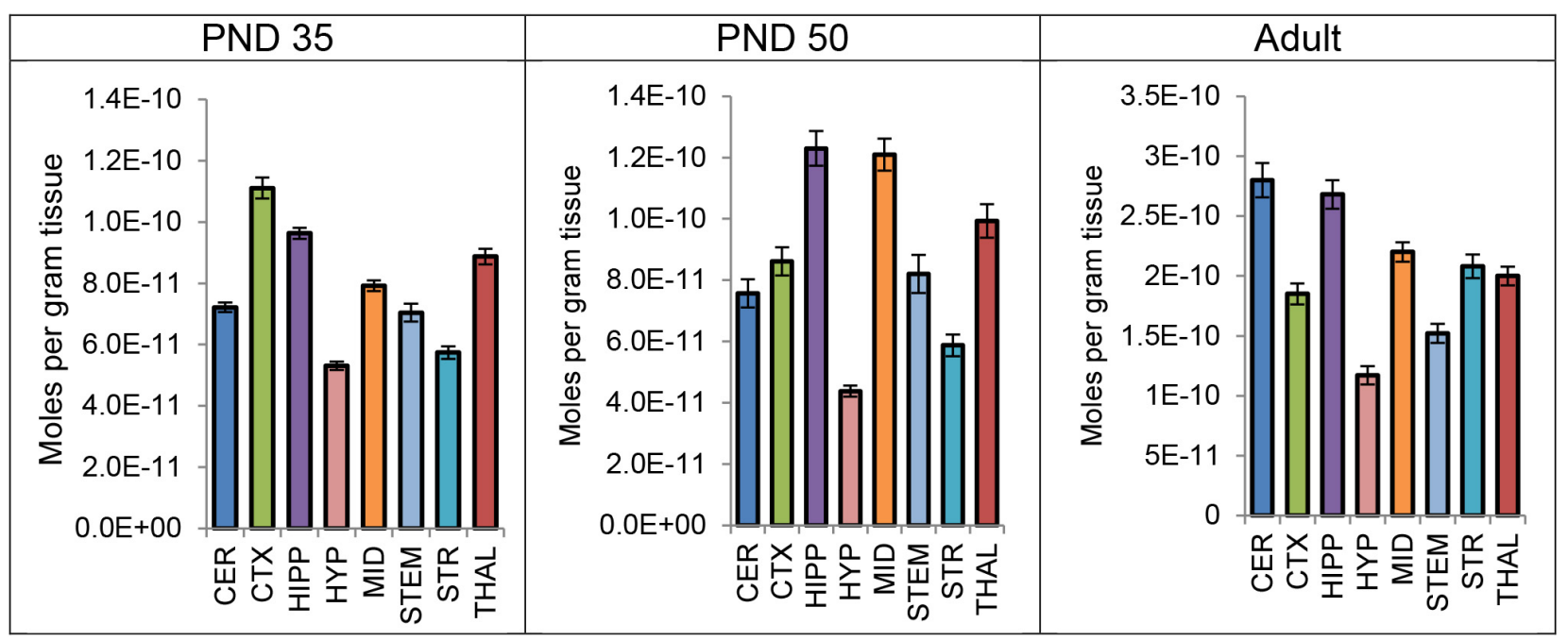

FIGURE 5 | Average level of CP 55,940 in each of eight brain regions in post-natal day (PND) 35 adolescent, PND 50 adolescent, and adult female CD1 mice 2 h after a single systemic $3 \mathrm{mg} / \mathrm{kg}$ CP 55,940 injection. Lipid levels are in moles per gram of tissue and error bars represent the standard error of the mean. CER, cerebellum; CTX, cortex; HIPP, hippocampus; HYP, hypothalamus; MID, midbrain; STEM, brainstem; STR, striatum; THAL, thalamus.

A-GABA, and A-Taur. A-GABA decreased in the HIPP, CER, THAL, and HYP. A-Taur levels fell in the CER, CTX, and STEM, but rose in the HYP (Figure 4). Overall, it appears that acute CP may mainly reduce signaling abilities of AA-derived lipoamines, and this effect is more profound in the adolescent brain.

\section{CP Levels Vary by Brain Region After Acute Administration}

Levels of CP were measured in each brain region $2 \mathrm{~h}$ after a systemic $3 \mathrm{mg} / \mathrm{kg}$ CP injection in PND 35, PND 50, and adult mice. A one-way ANOVA revealed a main effect of brain area on mean levels of CP in all three age groups, with levels varying twofold to threefold among the eight brain regions. Thus, the distribution of CP is not uniform throughout the brain $2 \mathrm{~h}$ after a single CP injection. In all three age groups, levels of CP were lowest in the HYP of the eight brain areas. However, the area with the highest levels of CP differed by age. In the PND 35 brain, levels of CP were highest in the CTX; in the PND 50 brain, levels of CP were highest in the HIPP; in the adult brain, levels of CP were highest in the CER (Figure 5). Please refer to the Supplementary Tables 49-54 for the full set descriptive statistics and ANOVA results regarding the distribution of CP amongst the eight brain areas.

\section{DISCUSSION}

CP 55,940 and other synthetic cannabinoids are highly potent and efficacious $\mathrm{CB}_{1}$ agonists associated with extreme psychological and physiological effects (Hudson and Ramsey, 2011; Castaneto et al., 2014; Fantegrossi et al., 2014; Davidson et al., 2017; Moeller et al., 2017; Samra et al., 2017; Manix et al., 2018). While there are similarities in some physiological effects between cannabis and synthetic cannabinoids, life-threatening reactions which have been attributed to synthetic cannabinoids are not associated with cannabis use alone (Underwood, 2015; Davidson et al., 2017; Manix et al., 2018). This is mostly attributed to higher potency and efficacy at $\mathrm{CB}_{1}$ (Pacher et al., 2018), although there are also "off-target" effects of synthetic cannabinoids and differences in metabolism that may be driving these adverse effects (Fantegrossi et al., 2014). The use of synthetic cannabinoids is prevalent in vulnerable populations such as adolescents (Gilbert et al., 2015; Müller et al., 2015). Here, we demonstrate that CP drives significant changes in the CNS lipidome that include but go well-beyond AEA and 2-AG, and that an acute dose of $\mathrm{CP}$ affects more lipids in the adolescent brain than the adult. Our data suggests that adolescents may be at particular risk for CNS insults with the use of synthetic cannabinoids, contributing to growing evidence that the use of $\mathrm{CB}_{1}$-acting drugs in adolescence is more harmful than during adulthood (O'Shea et al., 2004; Quinn et al., 2008; Abboussi et al., 2014; Moretti et al., 2014; Rubino and Parolaro, 2014, 2015).

\section{$3 \mathrm{mg} / \mathrm{kg}$ CP Is Relevant for Synthetic Cannabinoid Abuse and Has Stronger Effects on the Female Mouse Brain Lipidome During Adolescence}

The dose of $3 \mathrm{mg} / \mathrm{kg}$ was chosen to match the dose used in our previous analysis of the effects of acute THC on the lipidome of adolescent and adult female mouse brain regions (Leishman et al., 2018). $3 \mathrm{mg} / \mathrm{kg}$ THC was estimated to be equivalent to smoking 1 joint for humans (Zamberletti et al., 2012). Given the differences in potency and efficacy between CP and $\mathrm{THC}$, the degree of $\mathrm{CB}_{1}$ activation would be much greater after $3 \mathrm{mg} / \mathrm{kg}$ CP compared to $3 \mathrm{mg} / \mathrm{kg}$ THC. However, synthetic cannabinoid users do not typically consider the differences in potency. Many people use synthetic cannabinoids in the same 
manner as natural cannabinoids, meaning that if they normally smoke 1 joint of cannabis, then they will smoke 1 joint of spice, even if this causes a much stronger intoxication (Lapoint et al., 2011). Indeed, popular press articles sometime refer to synthetic cannabinoid users as "spice zombies" because of drug-induced catalepsy (Alexandrescu, 2018; BBC News, 2018). Providing more evidence of failure to titrate dose based on potency, patients seeking treatment for synthetic cannabinoid abuse consumed significantly more drug (4.05 g/day) than those for cannabis use disorder (2.31 g/day) (Cengel et al., 2018). CP has not been found in spice, likely due to the fact that it was a known $\mathrm{CB}_{1}$ agonist and easily measured by law enforcement. However, given that CP is a canonical synthetic cannabinoid (Lefever et al., 2017) and that $\mathrm{CP}$ analogs with similar potency at $\mathrm{CB}_{1}$ were identified in spice products (Uchiyama et al., 2009b; Hermanns-Clausen et al., 2013), CP is a suitable candidate to model synthetic cannabinoid abuse. At the $3 \mathrm{mg} / \mathrm{kg}$ dose, there were more changes in the female mouse brain lipidome as a consequence of acute CP exposure compared to acute THC exposure, although both drugs reduced eCB levels in some brain areas. This difference was most apparent in the PND 35 brain (Leishman et al., 2018). A follow-up study could use equipotent doses of CP and THC based on tetrad effects to help determine if the increased impact of CP on the lipidome relative to $\mathrm{THC}$ is due to increased potency. However, $\mathrm{CP}$ and THC are not specific to $\mathrm{CB}_{1}$ and $\mathrm{CP}$ can also activate $\mathrm{CB}_{2}$ and GPR55 (Ryberg et al., 2007). To examine the contribution of $\mathrm{CB}_{1}$ to the effects of $\mathrm{CP}$ and $\mathrm{THC}$ on the lipidome, a $\mathrm{CB}_{1}$ antagonist could be co-administered with $\mathrm{CP}$ and with THC in future studies.

In both the present study and the THC study, we chose to examine female mice. In the rodent literature, the effects of adolescent exposure to $\mathrm{CP}$ were often more severe in females (Biscaia et al., 2003, 2008; Higuera-Matas et al., 2008; Mateos et al., 2011). This is also the case with THC (Zamberletti et al., 2012). Although most of the people who experienced adverse reactions from synthetic cannabinoids were male, there are also documented cases of acute detrimental effects of synthetic cannabinoids in young women involving emergency room visits (Schneir et al., 2011). The higher prevalence of adverse effects in men might be due to higher rates of risky behavior in general. However, more recent surveys demonstrate that male and female adolescents are now equally likely to use illegal drugs (Becker et al., 2017). Making it important to study the effects of drugs of abuse in both sexes, there are sex differences at every stage of drug abuse and addiction (Becker et al., 2017). For example, women tend to increase the rate of alcohol, marijuana, opioids, and cocaine use more rapidly than men do (Lynch et al., 2002). These sex differences as well as the worrying increase in drug use amongst young women in recent years mean that females are worth examining. Follow up studies should test whether some of the effects of acute CP on the lipidome are sex dependent.

CP 55,940 may have developmental-dependent effects because the eCB system is dynamic throughout adolescence (Heng et al., 2011; Lee et al., 2013). We selected to use PND 35 (mid adolescent) and PND 50 (older adolescent) mice to determine whether changes in the lipidome in response to THC and CP are sensitive to the stage of adolescence. There is evidence that levels of AEA are higher in the PND 35 and young adult amygdala, HYP, prefrontal cortex, and HIPP compared to in these areas at PND 45. This was also the case with OEA and PEA and demonstrates that there is fluctuation in NAE production during development, with levels increasing, decreasing, and then increasing again (Lee et al., 2013). However, this study was performed in rats and there needs to be a more investigation whether this is the case in mice and whether lipoamines beyond NAEs follow a similar pattern. In male rats, levels of 2-AG were measured during adolescence in the pre-frontal cortex (Ellgren et al., 2008). 2-AG levels were highest at PND 29, then declined in mid adolescence (PND 38), before increasing again during late adolescence (PND 50) (Ellgren et al., 2008). In the same set of experiments, a different pattern was uncovered with AEA, wherein levels gradually increased during adolescence (Ellgren et al., 2008). In the female rat pre-frontal cortex, increases in AEA were found from PND 46-60, but decreases were measured between PND 60 and 70. However, no significant changes in 2AG, MAGL, or FAAH were found in these rats (Rubino et al., 2015). Studies suggest $\mathrm{CB}_{1}$ expression is higher during early adolescence and declines with age (Ellgren et al., 2008; Heng et al., 2011; Lee and Gorzalka, 2012). Although there are discrepancies in the literature, which may be partially due to species and sex differences, the most consistent pattern is that $\mathrm{eCB}$ ligands fluctuate during adolescence, whereas $\mathrm{CB}_{1}$ expression peaks during early adolescence and declines toward adulthood (Lee et al., 2016). The relatively higher levels of $\mathrm{CB}_{1}$ in the PND 35 brain may potentially explain why a drug that strongly activates $\mathrm{CB}_{1}$ like $\mathrm{CP}$ had more effects at this time point.

\section{CP Causes Catalepsy and May Drive Neuroinflammation}

Mice treated with CP in this study were most-likely cataleptic, as they had reduced locomotor activity. Showing that the dose given in this study was more than enough to produce catalepsy, the $\mathrm{ED}_{50}$ of CP is $0.4 \mathrm{mg} / \mathrm{kg}$ for catalepsy (Little et al., 1988; Compton et al., 1992). A single $0.3 \mathrm{mg} / \mathrm{kg}$ injection of CP produced catalepsy in $\mathrm{C} 57$ mice, but not in $\mathrm{CB}_{1} \mathrm{KO}$ mice. This provides further evidence that the characteristic behavioral signs of CP consumption are mediated by $\mathrm{CB}_{1}$ (Kow et al., 2014). Catalepsy is linked to psychopathologies including schizophrenia (Fink et al., 2009). Recent translational studies have implicated abnormalities in the myelin protein CNP in the development of catalepsy. Reduced CNP levels generate neuroinflammation and reducing inflammation ameliorated catalepsy in mice (PeaseRaissi and Chan, 2018). The eCB system regulates inflammation, with AEA and 2-AG typically having anti-inflammatory effects (Donvito et al., 2017). The fact that these lipids decreased with CP means that the risk of neuroinflammation could potentially increase after CP exposure. Other AA-derived lipoamines are noted to have anti-inflammatory effects in the CNS, such as A-Ser and NAGly (Hanuš et al., 2014). A-Ser and NAGly decreased in some brain areas of CP-exposed mice, especially in PND 35 mice, suggesting a pro-inflammatory lipid environment in these regions that might contribute to catalepsy. CP's effects on $\mathrm{CB}_{2}$ might affect the brain's ability to respond to inflammatory 
stimuli, as $\mathrm{CB}_{2}$ is expressed on microglia (Merighi et al., 2012). Furthermore, there is now evidence that microglia have a role in healthy brain development, as they can support synapses (Lenz and McCarthy, 2015). $\mathrm{CB}_{2}$ can also be desensitized after $24 \mathrm{~h}$ exposure to $\mathrm{CP}$ (Shoemaker et al., 2005), so this receptor might also contribute to longer term effects of $\mathrm{CP}$. $\mathrm{CB}_{2} \mathrm{KO}$ mice show some schizophrenia-like behaviors (Ortega-Alvaro et al., 2011), and adolescent exposure to cannabinoid receptor agonists is linked to increased risk of developing schizophrenia (Murray et al., 2017). Therefore, the contribution of $\mathrm{CB}_{2}$ to detrimental effects of synthetic cannabinoids should also be examined, even if the actions at $\mathrm{CB}_{2}$ are not causing immediate behavioral effects.

\section{Motivation and Psychosis - Effects on Dopaminergic Circuitry}

Acutely, $\mathrm{CP}$ can decrease female sexual motivation, a process reliant on dopamine transmission. However, doses of over $0.4 \mathrm{mg} / \mathrm{kg}$ also attenuated social motivation (Ferrari et al., 2000; Lopez et al., 2009; Gorzalka et al., 2010), suggesting a general effect on motivational circuitry. This circuitry is considered part of the brain's reward system and is also critical for the neurobiology of addiction (Koob and Volkow, 2010). In preclinical models, the use of $\mathrm{CP}$ during adolescence has been linked to increased administration of drugs of abuse like cocaine or morphine during adulthood (Biscaia et al., 2008; Higuera-Matas et al., 2010). Higuera-Matas et al. (2010) gave rats a daily $0.4 \mathrm{mg} / \mathrm{kg}$ CP injection from PND 28 until PND 38 . At PND 75, cocaine self-administration was measured. Female rats exposed to $\mathrm{CP}$ during adolescence administered significantly more cocaine than rats exposed to vehicle. The use of $\mathrm{CP}$ and the increase in cocaine self-administration were correlated with changes in expression of genes encoding proteins of the striatal and hippocampal dopaminergic circuitry (Higuera-Matas et al., 2010). Specifically, CP administration during adolescence upregulated the DAT in the caudate-putamen and decreased dopamine D2 receptor levels in the HIPP (Higuera-Matas et al., 2010). Therefore, the non-voluntary exposure of rats to $\mathrm{CP}$ during adolescence has short and long-term impacts on motivated behaviors, potentially by down-regulating dopamine receptor expression and upregulating levels of DAT.

Excessive dopamine signaling is involved in psychosis and dopamine D2 receptors are often a target for anti-psychotic drugs (Howes and Kapur, 2009). Effects of synthetic cannabinoids on the dopaminergic system might contribute to the psychosis seen in users. CP is aversive to rodents (McGregor et al., 1996) and aversive stimuli can actually increase dopamine transmission (Brischoux et al., 2009), which could drive psychosis-like symptoms. Additionally, there is evidence that $\mathrm{CB}_{1}$ activation drives dopamine release (French et al., 1997), making it likely that acute doses of $\mathrm{CP}$ increase dopamine signaling even without evidence of rewarding effects. 2-AG signaling may act to dampen dopamine release (Oleson and Cheer, 2012), meaning that reductions in 2-AG found in the CP-exposed brain areas may trigger dopamine release. Administration of THC and the synthetic analog, Nabilone, can produce schizophrenia-like symptoms in otherwise healthy adults (Murray et al., 2017).
These symptoms can be ameliorated by the plant cannabinoid $\mathrm{CBD}$, which has generated the hypothesis that $\mathrm{CB}_{1}$-activating cannabinoids are psychotomimetic, whereas those that negatively modulate $\mathrm{CB}_{1}$ can be anti-psychotic (Murray et al., 2017). Interestingly, there may be opposing effects of $\mathrm{CBD}$ and $\mathrm{CP}$ on levels of AEA. For example, CBD increased levels of AEA in BV-2 microglial cells (Rimmerman et al., 2012) and in the CSF of patients with schizophrenia, correlating with improved symptoms (Leweke et al., 2012). In contrast, levels of AEA instead tended to decrease in brains exposed to $\mathrm{CP}$ and in adult brains exposed to THC (Leishman et al., 2018). Therefore, alterations in AEA may be indicative of whether a drug has pro-psychotic or anti-psychotic effects.

What mechanisms could lead to a reduction in AEA? There are multiple pathways to yield AEA from its precursor $N$-acyl phosphatidylethanolamine (NAPE), but the most direct is NAPE's hydrolysis by a NAPE-specific phospholipase D (NAPEPLD) (Di Marzo et al., 1994). In the less direct, alternative pathways: intermediates lyso-NAPE (Simon and Cravatt, 2006) or phospho-AEA (Liu et al., 2006) are synthesized from NAPE and are further processed to produce AEA. Reductions in brain levels of AEA and NAEs could be driven by inhibition of NAPEPLD. Our previous study of NAPE-PLD KO mice demonstrated that NAPE-PLD deletion downregulates NAEs. PGs are also upregulated in NAPE-PLD KO brain areas, but there were very few changes in 2-acyl glycerols (Leishman et al., 2016a). This makes NAPE-PLD a more likely candidate to drive the decreases in AEA in areas like the PND 50 HIPP, where all 3 PGs increased and AEA decreased, but wherein there were no effects on AA or 2-AG. However, there may be other pathways contributing to the effects of CP outside of NAPE-PLD inhibition. NAPEPLD activity can be measured using recombinant enzymes and inhibitors of NAPE-PLD are now available (Castellani et al., 2017) to more directly test this hypothesis. AEA is primarily hydrolyzed by fatty acid amide hydrolase (FAAH) (Cravatt et al., 1996). Therefore, an alternative hypothesis is that $\mathrm{CP}$ upregulates FAAH activity to decrease AEA levels. Previous work by our group in FAAH KO mice has demonstrated that FAAH deletion increases AEA at the expense of AA-derived lipoamines such as NAGly and has no effect on PGs or free AA (Leishman et al., 2016a). The fact that these lipids changed with $\mathrm{CP}$ calls into question whether it is acting on FAAH. However, the consequences of FAAH upregulation on the lipidome have not yet been examined. To test whether FAAH is required for $\mathrm{CP}$ to decrease AEA, our acute $\mathrm{CP}$ experiments can be repeated in FAAH KO mice.

\section{CP Distribution}

CP 55,940 is a member of the cyclohexylphenol category of synthetic cannabinoids, whose structures are different from classical cannabinoids like THC and are instead bicyclic (Hudson and Ramsey, 2011). However, CP is still lipophilic in nature and can be detected using similar methods to the detection of THC: lipid extraction and analysis with liquid (or gas) chromatography and mass spectrometry (Uchiyama et al., 2009a; Hudson and Ramsey, 2011). Previously, we showed that THC levels were highest in the HIPP after acute exposure across all age groups (Leishman et al., 2018). Similarly, here, hippocampal 
$\mathrm{CP}$ levels were among the two highest brain regions across all age groups. Correlated with enriched $\mathrm{CB}_{1}$ expression in the HIPP (Herkenham et al., 1990), the enriched levels of CP in the HIPP may contribute to deficits in learning and memory (Han et al., 2012) and emotional processing (Loureiro et al., 2016). In contrast to THC, levels of CP were lowest in the HYP across all age groups. One potential explanation is localized metabolism of CP. However, standards for CP metabolites are not readily available for analysis (Jin et al., 2013). It is possible that like THC's primary metabolite, 11-OH-THC (Lemberger et al., 1972), some of the CP metabolites may have behavioral effects.

\section{Potential Mechanisms of CP on CNS Lipidome Regulation}

One of the signatures of acute CP on the lipidome was a widespread reduction in lipid levels, especially in levels of lipids derived from AA. High levels of $\mathrm{CB}_{1}$ activation may partially underlie these effects. Activating $\mathrm{CB}_{1}$ on a presynaptic neuron can decrease neurotransmitter release (Wilson and Nicoll, 2001). However, neurotransmitter release can trigger $\mathrm{eCB}$ production in the post-synaptic neuron ( $\mathrm{Lu}$ and Mackie, 2016). As there is now less neurotransmitter release this could in turn decrease the release of eCBs. The production of eCBs depends on the availability of precursors and enzymes. Although CP affected more lipids than eCBs, this implicates eCB system enzymes as potential mediators of CP's effects because these enzymes regulate lipid levels beyond $\mathrm{eCB}$ substrates, including those of the AA family (Leishman et al., 2016a,b; Bradshaw and Leishman, 2017). DAGLs synthesize 2-acyl glycerols (Bisogno et al., 2003). The DAGL $\alpha$ isoform appears more important for biosynthesis of 2AG in the brain, whereas the DAGL $\beta$ isoform appears more important in the periphery and immune cells (Reisenberg et al., 2012). Along with 2-AG levels, AEA levels were downregulated in the CER, STR, and HIPP of a line of DAGL $\alpha$ KO mice (Tanimura et al., 2010). Another line of DAGL $\alpha$ KO had an $80 \%$ reduction in whole brain 2-AG and AA levels and a $40 \%$ reduction in AEA (Gao et al., 2010). A third line of DAGL $\alpha$ KO had reduced levels of 2-AG and AA in the forebrain, but did not detect a significant reduction in AEA in this area, hinting at some regional specificity for the contribution of DAGL $\alpha$ activity to AEA levels (Shonesy et al., 2014). Reductions in whole-brain 2-AG, AA, and AEA also occur when DAGL $\alpha$ is pharmacologically inhibited (Ogasawara et al., 2016). The reductions in 2-AG, AA, and AEA levels were temporary, being measured at $2 \mathrm{~h}$ and $4 \mathrm{~h}$ post-injection of the DAGL $\alpha$ inhibitor DH376 and returning to baseline by $8 \mathrm{~h}$ (Ogasawara et al., 2016). It is thus possible that DAGL is inhibited in the brains of mice exposed to $\mathrm{CP}$, as DAGL inhibition could cause a concurrent decrease in 2-AG, AA, and AEA that could be detected at $2 \mathrm{~h}$.

It is not yet known how levels of AA-derived lipoamines change in DAGL $\alpha$ KO or with DAGL $\alpha$ inhibitors, as a full lipidomics screen of multiple brain areas has not yet been applied to DAGL $\alpha \mathrm{KO}$ or to mice exposed to DAGL $\alpha$-blocking drugs. However, if levels of AA-derived lipoamines are reduced when DAGL $\alpha$ is blocked, then that would provide a stronger suggestion of that enzyme's role in CP's effects on the lipidome.
Follow-up studies can determine if the effects of acute CP are abolished when DAGL $\alpha$ is inhibited or deleted. If CP's effects on the lipidome require DAGL $\alpha$, then more direct measurements of DAGL $\alpha$ activity can be performed in the presence of various concentrations of CP. Recently, a fluorescent probe was developed to measure DAGL $\alpha$ activity (van der Wel et al., 2015). This probe can be used in ABPP assays on cells overexpressing DAGL (Hsu et al., 2012) or in mouse brain proteasomes (Baggelaar et al., 2013). By performing ABPP in the presence and absence of CP, then CP inhibition of DAGL $\alpha$ can be quantified. Another advantage of ABPP is the ability to detect off-target serine hydrolase activity by incubating with an FP-biotin probe (Liu et al., 1999), which may reveal an even more widespread impact of acute CP on enzymes important for maintaining levels of bioactive lipids.

One of the roles of $2-A G$ is in appetite stimulation and CP might potentially reduce appetite by acting on 2-AG. An acute injection of $0.1 \mathrm{mg} / \mathrm{kg} \mathrm{CP}$ in rats produced anorexic effects lasting up to $24 \mathrm{~h}$ (McGregor et al., 1996). Two additional studies demonstrated that food intake was temporarily reduced when rats were given chronic injections of CP in adolescence (Biscaia et al., 2003; Mateos et al., 2011). Data here shows that PND 35 and PND 50 adolescent mice had lower levels of 2-AG in the HYP after acute CP. The HYP is an important region for appetite regulation and feeding behavior and 2-AG stimulates eating (Kirkham et al., 2002). Thus, reductions in 2-AG in the HYP could contribute to anorexic effects of CP. People who are overweight or obese tend to have higher circulating levels of eCBs (Di Marzo, 2008). However, giving them CP would not be an ideal, due to the effects on locomotion and cognition. Instead, if we can elucidate some of the pathways used by CP to reduce lipid levels, we can develop a more targeted drug to ameliorate the disruptions in lipid metabolism. For example, a DAGL inhibitor could be used instead of CP. Indeed, there are already groups working on developing DAGL inhibitors for metabolic disorders, after it was noted that DAGL KO animals are leaner and consume less food than WT littermates (Janssen and van der Stelt, 2016). DAGL inhibitors are also being investigated for inflammatory pain (Wilkerson et al., 2017), which could replicate some of the analgesic effects of CP without the abuse liability.

As revealed by proteomics, a structurally similar drug to CP with similar pharmacology, CP 47,497-C8, alters expression of multiple enzymes involved in lipid metabolism. Specifically, when human peripheral blood mononuclear cells were stimulated with $10 \mu \mathrm{M}$ CP 47,497-C8 for $3 \mathrm{~h}$, expression of 5-LOX was upregulated 26-fold compared to vehicle, expression of fatty acid synthase increased over twofold, and expression of group XV phospholipase A2, long-chain-fatty-acid-CoA ligase 1, ABHD12, phospholipase D1, and thromboxane-A synthase significantly increased (Bileck et al., 2016). These enzymes are all involved in inflammation and levels of pro-inflammatory cytokines increased in the cells exposed to CP 47,497-C8 (Bileck et al., 2016). There was also evidence of DNA damage in these cells caused by inhibition of repair mechanisms (Bileck et al., 2016). Inflammation and DNA damage may contribute to the adverse health outcomes in synthetic cannabinoid users (Bileck et al., 2016). Because CP is so structurally similar, it is 
possible that $\mathrm{CP}$ has similar effects on enzyme levels, but this has not yet been tested. The increase in ABHD12 is of particular interest because it is involved in 2-acyl glycerol hydrolysis (Savinainen et al., 2012). An increase in ABHD12 activity may contribute to reductions in 2-acyl glycerols. Decreases in AA and its derivatives may also be driven by an increase in 5-LOX activity (Rouzer and Marnett, 2011). The widespread effect of CP on lipid levels may be due to its ability to affect multiple enzymes involved in lipid metabolism.

\section{CONCLUSION}

The potent and efficacious synthetic cannabinoid, CP, affects the lipidome in a brain-region and development-dependent manner and appears to have far-reaching effects on multiple lipid signaling pathways. These effects were region and age-dependent providing additional clues to how the consequences of this specific class of drugs of abuse must be considered differentially between populations. Overall, acute CP altered the levels of more lipids in younger brains, suggesting that dysregulation of the lipidome is more vulnerable to $\mathrm{CP}$ during adolescence. $\mathrm{CP}$ caused region-dependent reductions in eCB levels, possibly due to $\mathrm{CB}_{1}$ activation. Future studies will compare the effects of THC and $\mathrm{CP}$ using $\mathrm{CB}_{1} \mathrm{KO}$ mice and $\mathrm{CB}_{1}$ antagonists to better determine the contribution of $\mathrm{CB}_{1}$ activity. However, the effects of CP are not only more widespread in the CNS; they have dramatically more impact in the adolescent. Understanding

\section{REFERENCES}

Abboussi, O., Tazi, A., Paizanis, E., and El Ganouni, S. (2014). Chronic exposure to WIN55,212-2 affects more potently spatial learning and memory in adolescents than in adult rats via a negative action on dorsal hippocampal neurogenesis. Pharmacol. Biochem. Behav. 120, 95-102. doi: 10.1016/j.pbb.2014.02.014

Alexandrescu, L. (2018). 'Ethnobotanicals' and 'Spice zombies': new psychoactive substances in the mainstream media. Drugs Educ. Prev. Policy 25, 356-364. doi: 10.1080/09687637.2017.1397101

Baggelaar, M. P., Janssen, F. J., van Esbroeck, A., den Dulk, H., Allarà, M., Hoogendoorn, S., et al. (2013). Development of an activity-based probe and in silico design reveal highly selective inhibitors for diacylglycerol lipase- $\alpha$ in brain. Angew. Chem. Int. Ed. 52, 12081-12085. doi: 10.1002/anie.201306295

BBC News (2018). 'Devastating' Impact of 'Spice' Shown in Image in Bridgend. London: BBC News.

Becker, J. B., McClellan, M. L., and Reed, B. G. (2017). Sex differences, gender and addiction. J. Neurosci. Res. 95, 136-147. doi: 10.1002/jnr.23963

Besnard, J., Ruda, G. F., Setola, V., Abecassis, K., Rodriguiz, R. M., Huang, X. P., et al. (2012). Automated design of ligands to polypharmacological profiles. Nature 492, 215-220. doi: 10.1038/nature11691

Bileck, A., Ferk, F., Al-Serori, H., Koller, V. J., Muqaku, B., Haslberger, A., et al. (2016). Impact of a synthetic cannabinoid (CP-47,497-C8) on protein expression in human cells: evidence for induction of inflammation and DNA damage. Arch. Toxicol. 90, 1369-1382. doi: 10.1007/s00204-015-1569-7

Biscaia, M., Fernández, B., Higuera-Matas, A., Miguéns, M., Viveros, M.-P., GarcíaLecumberri, C., et al. (2008). Sex-dependent effects of periadolescent exposure to the cannabinoid agonist CP-55,940 on morphine self-administration behaviour and the endogenous opioid system. Neuropharmacology 54, 863-873. doi: 10.1016/j.neuropharm.2008.01.006

Biscaia, M., Marín, S., Fernández, B., Marco, E. M., Rubio, M., Guaza, C., et al. (2003). Chronic treatment with CP 55,940 during the peri-adolescent period differentially affects the behavioural responses of male and female rats in adulthood. Psychopharmacology 170, 301-308. doi: 10.1007/s00213-003-1550-7 how synthetic cannabinoids differentially affect the brain and its development will allow us to better treat those who are using these drugs but will also allow us to better educate about their abuse liabilities.

\section{AUTHOR CONTRIBUTIONS}

EL performed all lipid extractions, collected and analyzed HPLC/MS/MS data, assisted with tissue collection, and prepared the manuscript. MNM and MIM performed drug and vehicle injections. KM provided the mice and assisted with manuscript preparation. HB designed the experiments, collected tissue, performed dissections, and prepared the manuscript.

\section{FUNDING}

The work was supported in part by National Institutes of Health grant numbers DA021696, DA024628, DA039463, and DA041208.

\section{SUPPLEMENTARY MATERIAL}

The Supplementary Material for this article can be found online at: https://www.frontiersin.org/articles/10.3389/fnmol. 2018.00436/full\#supplementary-material

Bisogno, T., Howell, F., Williams, G., Minassi, A., Cascio, M. G., Ligresti, A., et al. (2003). Cloning of the first snl-DAG lipases points to the spatial and temporal regulation of endocannabinoid signaling in the brain. J. Cell Biol. 163, 463-468. doi: $10.1083 /$ jcb.200305129

Bradshaw, H., and Allard, C. M. (2011). Endogenous cannabinoid production in the rat female reproductive tract is regulated by changes in the hormonal milieu. Pharmaceuticals 4, 933-949. doi: 10.3390/ph4060933

Bradshaw, H. B., and Leishman, E. (2017). Lipidomics: a corrective lens for enzyme myopia. Methods Enzymol. 593, 123-141. doi: 10.1016/bs.mie.2017.06.024

Bradshaw, H. B., Rimmerman, N., Hu, S. S., Benton, V. M., Stuart, J. M., Masuda, K., et al. (2009a). The endocannabinoid anandamide is a precursor for the signaling lipid $\mathrm{N}$-arachidonoyl glycine by two distinct pathways. BMC Biochem. 10:14. doi: 10.1186/1471-2091-10-14

Bradshaw, H. B., Rimmerman, N., Hu, S. S., Burstein, S., and Walker, J. M. (2009b). Novel endogenous $\mathrm{N}$-acyl glycines identification and characterization. Vitam. Horm. 81, 191-205. doi: 10.1016/S0083-6729(09)81008-X

Bradshaw, H. B., Rimmerman, N., Krey, J. F., and Walker, J. M. (2006). Sex and hormonal cycle differences in rat brain levels of pain-related cannabimimetic lipid mediators. Am. J. Physiol. Regul. Integr. Comp. Physiol. 291, R349-R358. doi: 10.1152/ajpregu.00933.2005

Brents, L. K., Reichard, E. E., Zimmerman, S. M., Moran, J. H., Fantegrossi, W. E., and Prather, P. L. (2011). Phase I hydroxylated metabolites of the K2 synthetic cannabinoid JWH-018 retain in vitro and in vivo cannabinoid 1 receptor affinity and activity. PLoS One 6:e21917. doi: 10.1371/journal.pone.0021917

Brischoux, F., Chakraborty, S., Brierley, D. I., and Ungless, M. A. (2009). Phasic excitation of dopamine neurons in ventral VTA by noxious stimuli. Proc. Natl. Acad. Sci. U.S.A. 106, 4894-4899. doi: 10.1073/pnas.0811507106

Castaneto, M. S., Gorelick, D. A., Desrosiers, N. A., Hartman, R. L., Pirard, S., and Huestis, M. A. (2014). Synthetic cannabinoids: epidemiology, pharmacodynamics, and clinical implications. Drug Alcohol Depend. 144, $12-$ 41. doi: 10.1016/j.drugalcdep.2014.08.005

Castellani, B., Diamanti, E., Pizzirani, D., Tardia, P., Maccesi, M., Realini, N., et al. (2017). Synthesis and characterization of the first inhibitor of 
$\mathrm{N}$-acylphosphatidylethanolamine phospholipase D (NAPE-PLD). Chem. Commun. 53, 12814-12817. doi: 10.1039/c7cc07582k

Cengel, H. Y., Bozkurt, M., Evren, C., Umut, G., Keskinkilic, C., and Agachanli, R. (2018). Evaluation of cognitive functions in individuals with synthetic cannabinoid use disorder and comparison to individuals with cannabis use disorder. Psychiatry Res. 262, 46-54. doi: 10.1016/j.psychres.2018.01.046

Chadwick, B., Saylor, A. J., and Lopez, H. H. (2011). Adolescent cannabinoid exposure attenuates adult female sexual motivation but does not alter adulthood CB1R expression or estrous cyclicity. Pharmacol. Biochem. Behav. 100, 157-164. doi: 10.1016/j.pbb.2011.07.006

Compton, D. R., Johnson, M. R., Melvin, L. S., and Martin, B. R. (1992). Pharmacological profile of a series of bicyclic cannabinoid analogs: classification as cannabimimetic agents. J. Pharmacol. Exp. Ther. 260, 201-209.

Console-Bram, L., Brailoiu, E., Brailoiu, G. C., Sharir, H., and Abood, M. E. (2014), Activation of GPR18 by cannabinoid compounds: a tale of biased agonism. $\mathrm{Br}$. J. Pharmacol. 171, 3908-3917. doi: 10.1111/bph.12746

Console-Bram, L., Ciuciu, S. M., Zhao, P., Zipkin, R. E., Brailoiu, E., and Abood, M. E. (2017). N-arachidonoyl glycine, another endogenous agonist of GPR55. Biochem. Biophys. Res. Commun. 490, 1389-1393. doi: 10.1016/j.bbrc.2017.07.038

Cravatt, B. F., Giang, D. K., Mayfield, S. P., Boger, D. L., Lerner, R. A., and Gilula, N. B. (1996). Molecular characterization of an enzyme that degrades neuromodulatory fatty-acid amides. Nature 384, 83-87. doi: 10.1038/384083a0

Davidson, C., Opacka-Juffry, J., Arevalo-Martin, A., Garcia-Ovejero, D., MolinaHolgado, E., and Molina-Holgado, F. (2017). Spicing up pharmacology: a review of synthetic cannabinoids from structure to adverse events. Adv. Pharmacol. 80, 135-168. doi: 10.1016/bs.apha.2017.05.001

Devane, W. A., Dysarz, F. R., Johnson, M. R., Melvin, L. S., and Howlett, A. C. (1988). Determination and characterization of a cannabinoid receptor in rat brain. Mol. Pharmacol. 34, 605-613.

Devane, W. A., Hanus, L., Breuer, A., Pertwee, R. G., Stevenson, L. A., Griffin, G., et al. (1992). Isolation and structure of a brain constituent that binds to the cannabinoid receptor. Science 258, 1946-1949. doi: 10.1126/science.1470919

Di Marzo, V. (2008). The endocannabinoid system in obesity and type 2 diabetes. Diabetologia 51, 1356-1367. doi: 10.1007/s00125-008-1048-2

Di Marzo, V., Fontana, A., Cadas, H., Schinelli, S., Cimino, G., Schwartz, J. C., et al. (1994). Formation and inactivation of endogenous cannabinoid anandamide in central neurons. Nature 372, 686-691. doi: 10.1038/372686a0

Donvito, G., Nass, S. R., Wilkerson, J. L., Curry, Z. A., Schurman, L. D., Kinsey, S. G., et al. (2017). The endogenous cannabinoid system: a budding source of targets for treating inflammatory and neuropathic pain. Neuropsychopharmacology 43, 52-79. doi: 10.1038/npp.2017.204

Ellgren, M., Artmann, A., Tkalych, O., Gupta, A., Hansen, H. S., Hansen, S. H., et al. (2008). Dynamic changes of the endogenous cannabinoid and opioid mesocorticolimbic systems during adolescence: THC effects. Eur. Neuropsychopharmacol. 18, 826-834. doi: 10.1016/j.euroneuro. 2008.06.009

Fantegrossi, W. E., Moran, J. H., Radominska-Pandya, A., and Prather, P. L. (2014). Distinct pharmacology and metabolism of K2 synthetic cannabinoids compared to Delta(9)-THC: mechanism underlying greater toxicity? Life Sci. 97, 45-54. doi: 10.1016/j.lfs.2013.09.017

Felder, C. C., Joyce, K. E., Briley, E. M., Mansouri, J., Mackie, K., Blond, O., et al. (1995). Comparison of the pharmacology and signal transduction of the human cannabinoid CB1 and CB2 receptors. Mol. Pharmacol. 48, 443-450.

Ferrari, F., Ottani, A., and Giuliani, D. (2000). Inhibitory effects of the cannabinoid agonist HU 210 on rat sexual behaviour. Physiol. Behav. 69, 547-554. doi: 10.1016/S0031-9384(00)00214-6

Fink, M., Shorter, E., and Taylor, M. A. (2009). Catatonia is not schizophrenia: Kraepelin's error and the need to recognize catatonia as an independent syndrome in medical nomenclature. Schizophr. Bull. 36, 314-320. doi: 10.1093/ schbul/sbp059

French, E. D., Dillon, K., and Wu, X. (1997). Cannabinoids excite dopamine neurons in the ventral tegmentum and Substantia nigra. Neuroreport 8, 649652. doi: 10.1097/00001756-199702100-00014

Funk, C. D. (2001). Prostaglandins and leukotrienes: advances in eicosanoid biology. Science 294, 1871-1875. doi: 10.1126/science.294.5548.1871

Gao, Y., Vasilyev, D. V., Goncalves, M. B., Howell, F. V., Hobbs, C., Reisenberg, M., et al. (2010). Loss of retrograde endocannabinoid signaling and reduced adult neurogenesis in diacylglycerol lipase knock-out mice. J. Neurosci. 30, 20172024. doi: 10.1523/JNEUROSCI.5693-09.2010

Gilbert, M. T., Sulik, K. K., Fish, E. W., Baker, L. K., Dehart, D. B., and Parnell, S. E. (2015). Dose-dependent teratogenicity of the synthetic cannabinoid CP-55,940 in mice. Neurotoxicol. Teratol. 58, 15-22. doi: 10.1016/j.ntt.2015.12.004

Gorzalka, B. B., Hill, M. N., and Chang, S. C. (2010). Male-female differences in the effects of cannabinoids on sexual behavior and gonadal hormone function. Horm. Behav. 58, 91-99. doi: 10.1016/j.yhbeh.2009.08.009

Han, J., Kesner, P., Metna-Laurent, M., Duan, T., Xu, L., Georges, F., et al. (2012). Acute cannabinoids impair working memory through astroglial CB1 receptor modulation of hippocampal LTD. Cell 148, 1039-1050. doi: 10.1016/j.cell.2012. 01.037

Hanuš, L., Shohami, E., Bab, I., and Mechoulam, R. (2014). N-Acyl amino acids and their impact on biological processes. Biofactors 40, 381-388. doi: 10.1002/biof. 1166

Heng, L., Beverley, J. A., Steiner, H., and Tseng, K. Y. (2011). Differential developmental trajectories for $\mathrm{CB} 1$ cannabinoid receptor expression in limbic/associative and sensorimotor cortical areas. Synapse 65, 278-286. doi: 10.1002/syn.20844

Herkenham, M., Lynn, A. B., Little, M. D., Johnson, M. R., Melvin, L. S., de Costa, B. R., et al. (1990). Cannabinoid receptor localization in brain. Proc. Natl. Acad. Sci. U.S.A. 87, 1932-1936. doi: 10.1073/pnas.87.5.1932

Hermanns-Clausen, M., Kneisel, S., Szabo, B., and Auwarter, V. (2013). Acute toxicity due to the confirmed consumption of synthetic cannabinoids: clinical and laboratory findings. Addiction 108, 534-544. doi: 10.1111/j.1360-0443. 2012.04078.x

Higuera-Matas, A., Botreau, F., Del Olmo, N., Miguéns, M., Olías, Ó., Montoya, G. L., et al. (2010). Periadolescent exposure to cannabinoids alters the striatal and hippocampal dopaminergic system in the adult rat brain. Eur. Neuropsychopharmacol. 20, 895-906. doi: 10.1016/j.euroneuro.2010.06.017

Higuera-Matas, A., Soto-Montenegro, M. L., Del Olmo, N., Miguéns, M., Torres, I., Vaquero, J. J., et al. (2008). Augmented acquisition of cocaine self-administration and altered brain glucose metabolism in adult female but not male rats exposed to a cannabinoid agonist during adolescence. Neuropsychopharmacology 33, 806-813. doi: 10.1038/sj.npp.1301467

Howes, O. D., and Kapur, S. (2009). The dopamine hypothesis of schizophrenia: version III-the final common pathway. Schizophr. Bull. 35, 549-562. doi: 10. 1093/schbul/sbp006

Hsu, K.-L., Tsuboi, K., Adibekian, A., Pugh, H., Masuda, K., and Cravatt, B. F. (2012). DAGL $\beta$ inhibition perturbs a lipid network involved in macrophage inflammatory responses. Nat. Chem. Biol. 8, 999-1007. doi: 10.1038/nchembio. 1105

Huang, S. M., Bisogno, T., Petros, T. J., Chang, S. Y., Zavitsanos, P. A., Zipkin, R. E., et al. (2001). Identification of a new class of molecules, the arachidonyl amino acids, and characterization of one member that inhibits pain. J. Biol. Chem. 276, 42639-42644. doi: 10.1074/jbc.M107351200

Hudson, S., and Ramsey, J. (2011). The emergence and analysis of synthetic cannabinoids. Drug Test. Anal. 3, 466-478. doi: 10.1002/dta.268

Huestis, M. A., Boyd, S. J., Heishman, S. J., Preston, K. L., Bonnet, D., Le Fur, G., et al. (2007). Single and multiple doses of rimonabant antagonize acute effects of smoked cannabis in male cannabis users. Psychopharmacology 194, 505-515. doi: $10.1007 /$ s00213-007-0861-5

Janssen, F. J., and van der Stelt, M. (2016). Inhibitors of diacylglycerol lipases in neurodegenerative and metabolic disorders. Bioorg. Med. Chem. Lett. 26, 3831-3837. doi: 10.1016/j.bmcl.2016.06.076

Jin, M. J., Lee, J., In, M. K., and Yoo, H. H. (2013). Characterization of in vitro metabolites of CP 47,497, a synthetic cannabinoid, in human liver microsomes by LC-MS/MS. J. Forensic Sci. 58, 195-199. doi: 10.1111/j.1556-4029.2012. 02261.x

Jung, K. M., Astarita, G., Zhu, C., Wallace, M., Mackie, K., and Piomelli, D. (2007). A key role for diacylglycerol lipase-alpha in metabotropic glutamate receptordependent endocannabinoid mobilization. Mol. Pharmacol. 72, 612-621. doi: $10.1124 / \mathrm{mol} .107 .037796$

Kemp, A. M., Clark, M. S., Dobbs, T., Galli, R., Sherman, J., and Cox, R. (2016). Top 10 facts you need to know about synthetic cannabinoids: not so nice spice. Am. J. Med. 129, 240-244.e1. doi: 10.1016/j.amjmed.2015.10.008

Kirkham, T. C., Williams, C. M., Fezza, F., and Marzo, V. D. (2002). Endocannabinoid levels in rat limbic forebrain and hypothalamus in 
relation to fasting, feeding and satiation: stimulation of eating by 2 arachidonoyl glycerol. Br. J. Pharmacol. 136, 550-557. doi: 10.1038/sj. bjp. 0704767

Koob, G. F., and Volkow, N. D. (2010). Neurocircuitry of addiction. Neuropsychopharmacology 35, 217-238. doi: 10.1038/npp.2009.110

Kow, R. L., Jiang, K., Naydenov, A. V., Le, J. H., Stella, N., and Nathanson, N. M. (2014). Modulation of pilocarpine-induced seizures by cannabinoid receptor 1 . PLoS One 9:e95922. doi: 10.1371/journal.pone.0095922

Lapoint, J., James, L., Moran, C., Nelson, L., Hoffman, R., and Moran, J. (2011). Severe toxicity following synthetic cannabinoid ingestion. Clin. Toxicol. 49, 760-764. doi: 10.3109/15563650.2011.609822

Lee, T. T., Hill, M. N., Hillard, C. J., and Gorzalka, B. B. (2013). Temporal changes in $\mathrm{N}$-acylethanolamine content and metabolism throughout the peri-adolescent period. Synapse 67, 4-10. doi: 10.1002/syn.21609

Lee, T.-Y., and Gorzalka, B. (2012). Timing is everything: evidence for a role of corticolimbic endocannabinoids in modulating hypothalamic-pituitaryadrenal axis activity across developmental periods. Neuroscience 204, 17-30. doi: 10.1016/j.neuroscience.2011.10.006

Lee, T. Y., Hill, M. N., and Lee, F. S. (2016). Developmental regulation of fear learning and anxiety behavior by endocannabinoids. Genes Brain Behav. 15, 108-124. doi: $10.1111 / \mathrm{gbb} .12253$

Lefever, T. W., Marusich, J. A., Thomas, B. F., Barrus, D. G., Peiper, N. C., Kevin, R. C., et al. (2017). Vaping synthetic cannabinoids: a novel preclinical model of E-cigarette use in mice. Subst. Abuse 11:1178221817701739. doi: 10.1177/ 1178221817701739

Leishman, E., Cornett, B., Spork, K., Straiker, A., Mackie, K., and Bradshaw, H. B. (2016a). Broad impact of deleting endogenous cannabinoid hydrolyzing enzymes and the CB1 cannabinoid receptor on the endogenous cannabinoidrelated lipidome in eight regions of the mouse brain. Pharmacol. Res. 110, 159-172. doi: 10.1016/j.phrs.2016.04.020

Leishman, E., Mackie, K., Luquet, S., and Bradshaw, H. B. (2016b). Lipidomics profile of a NAPE-PLD KO mouse provides evidence of a broader role of this enzyme in lipid metabolism in the brain. Biochim. Biophys. Acta 1861, 491-500. doi: 10.1016/j.bbalip.2016.03.003

Leishman, E., Kunkler, P. E., Manchanda, M., Sangani, K., Stuart, J. M., Oxford, G. S., et al. (2017). Environmental toxin acrolein alters levels of endogenous lipids, including TRP agonists: a potential mechanism for headache driven by TRPA1 activation. Neurobiol. Pain 1, 28-36. doi: 10.1016/j.ynpai. 2017.03.001

Leishman, E., Murphy, M., Mackie, K., and Bradshaw, H. B. (2018). Delta(9)Tetrahydrocannabinol changes the brain lipidome and transcriptome differentially in the adolescent and the adult. Biochim. Biophys. Acta 1863, 479-492. doi: 10.1016/j.bbalip.2018.02.001

Lemberger, L., Crabtree, R. E., and Rowe, H. M. (1972). 11-hydroxy- 9 tetrahydrocannabinol: pharmacology, disposition, and metabolism of a major metabolite of marihuana in man. Science 177, 62-64. doi: 10.1126/science.177. 4043.62

Lenz, K. M., and McCarthy, M. M. (2015). A starring role for microglia in brain sex differences. Neuroscientist 21, 306-321. doi: 10.1177/1073858414536468

Leweke, F., Piomelli, D., Pahlisch, F., Muhl, D., Gerth, C., Hoyer, C., et al. (2012). Cannabidiol enhances anandamide signaling and alleviates psychotic symptoms of schizophrenia. Transl. Psychiatry 2:e94. doi: 10.1038/tp.2012.15

Little, P., Compton, D., Johnson, M., Melvin, L., and Martin, B. (1988). Pharmacology and stereoselectivity of structurally novel cannabinoids in mice. J. Pharmacol. Exp. Ther. 247, 1046-1051.

Liu, J., Wang, L., Harvey-White, J., Osei-Hyiaman, D., Razdan, R., Gong, Q., et al. (2006). A biosynthetic pathway for anandamide. Proc. Natl. Acad. Sci. U.S.A. 103, 13345-13350. doi: 10.1073/pnas.0601832103

Liu, Y., Patricelli, M. P., and Cravatt, B. F. (1999). Activity-based protein profiling: the serine hydrolases. Proc. Natl. Acad. Sci. U.S.A. 96, 14694-14699. doi: 10. 1073/pnas.96.26.14694

Lopez, H. H., Webb, S. A., and Nash, S. (2009). Cannabinoid receptor antagonism increases female sexual motivation. Pharmacol. Biochem. Behav. 92, 17-24. doi: 10.1016/j.pbb.2008.10.004

Loureiro, M., Kramar, C., Renard, J., Rosen, L. G., and Laviolette, S. R. (2016). Cannabinoid transmission in the hippocampus activates nucleus accumbens neurons and modulates reward and aversion-related emotional salience. Biol. Psychiatry 80, 216-225. doi: 10.1016/j.biopsych.2015.10.016
Lu, H. C., and Mackie, K. (2016). An introduction to the endogenous cannabinoid system. Biol. Psychiatry 79, 516-525. doi: 10.1016/j.biopsych. 2015.07.028

Lynch, W. J., Roth, M. E., and Carroll, M. E. (2002). Biological basis of sex differences in drug abuse: preclinical and clinical studies. Psychopharmacology 164, 121-137. doi: 10.1007/s00213-002-1183-2

Manix, D., Youssef, H., Ling, J., Desai, A., and Gulati, R. (2018). A case of synthetic cannabinoid induced ischemic stroke in a 20-year-old female. Curr. Trends Intern. Med. CTIM-106. doi: 10.29011/CTIM-106.100006

Mateos, B., Borcel, E., Loriga, R., Luesu, W., Bini, V., Llorente, R., et al. (2011). Adolescent exposure to nicotine and/or the cannabinoid agonist CP 55,940 induces gender-dependent long-lasting memory impairments and changes in brain nicotinic and CB1 cannabinoid receptors. J. Psychopharmacol. 25, 16761690. doi: $10.1177 / 0269881110370503$

McGregor, I. S., Issakidis, C. N., and Prior, G. (1996). Aversive effects of the synthetic cannabinoid CP 55,940 in rats. Pharmacol. Biochem. Behav. 53, 657-664. doi: 10.1016/0091-3057(95)02066-7

McHugh, D., Hu, S. S., Rimmerman, N., Juknat, A., Vogel, Z., Walker, J. M., et al. (2010). N-arachidonoyl glycine, an abundant endogenous lipid, potently drives directed cellular migration through GPR18, the putative abnormal cannabidiol receptor. BMC Neurosci. 11:44. doi: 10.1186/1471-2202-11-44

McHugh, D., Page, J., Dunn, E., and Bradshaw, H. B. (2012). Delta(9) -Tetrahydrocannabinol and $\mathrm{N}$-arachidonyl glycine are full agonists at GPR18 receptors and induce migration in human endometrial HEC1B cells. Br. J. Pharmacol. 165, 2414-2424. doi: 10.1111/j.1476-5381. 2011.01497.x

Mechoulam, R., Ben-Shabat, S., Hanus, L., Ligumsky, M., Kaminski, N. E., Schatz, A. R., et al. (1995). Identification of an endogenous 2-monoglyceride, present in canine gut, that binds to cannabinoid receptors. Biochem. Pharmacol. 50, 83-90. doi: 10.1016/0006-2952(95)00109-D

Merighi, S., Gessi, S., Varani, K., Fazzi, D., Mirandola, P., and Borea, P. A. (2012). Cannabinoid $\mathrm{CB}(2)$ receptor attenuates morphine-induced inflammatory responses in activated microglial cells. Br. J. Pharmacol. 166, 2371-2385. doi: 10.1111/j.1476-5381.2012.01948.x

Miech, R. A., Johnston, L. D., O'malley, P. M., Bachman, J. G., and Schulenberg, J. E. (2016). Monitoring the Future National Survey Results on Drug use, 19752015: Secondary School Students, Vol. I. Ann Arbor, MI: Institute for Social Research.

Moeller, S., Lucke, C., Struffert, T., Schwarze, B., Gerner, S. T., Schwab, S., et al. (2017). Ischemic stroke associated with the use of a synthetic cannabinoid (spice). Asian J. Psychiatr. 25, 127-130. doi: 10.1016/j.ajp.2016.10.019

Moretti, S., Castelli, M., Franchi, S., Raggi, M. A., Mercolini, L., Protti, M., et al. (2014). Delta(9)-Tetrahydrocannabinol-induced anti-inflammatory responses in adolescent mice switch to proinflammatory in adulthood. J. Leukoc. Biol. 96, 523-534. doi: 10.1189/jlb.3HI0713-406RR

Müller, H. H., Kornhuber, J., and Sperling, W. (2015). The behavioral profile of spice and synthetic cannabinoids in humans. Brain Res. Bull. 126(Pt 1), 3-7. doi: 10.1016/j.brainresbull.2015.10.013

Munro, S., Thomas, K. L., and Abu-Shaar, M. (1993). Molecular characterization of a peripheral receptor for cannabinoids. Nature 365, 61-65. doi: 10.1038/ $365061 \mathrm{a} 0$

Murray, R., Englund, A., Abi-Dargham, A., Lewis, D., Di Forti, M., Davies, C., et al. (2017). Cannabis-associated psychosis: neural substrate and clinical impact. Neuropharmacology 124, 89-104. doi: 10.1016/j.neuropharm. 2017.06.018

Ogasawara, D., Deng, H., Viader, A., Baggelaar, M. P., Breman, A., den Dulk, H., et al. (2016). Rapid and profound rewiring of brain lipid signaling networks by acute diacylglycerol lipase inhibition. Proc. Natl. Acad. Sci. U.S.A. 113, 26-33. doi: $10.1073 /$ pnas. 1522364112

Oleson, E. B., and Cheer, J. F. (2012). A brain on cannabinoids: the role of dopamine release in reward seeking. Cold Spring Harb. Perspect. Med. 2:a012229. doi: 10.1101/cshperspect.a012229

Ortega-Alvaro, A., Aracil-Fernández, A., García-Gutiérrez, M. S., Navarrete, F., and Manzanares, J. (2011). Deletion of CB 2 cannabinoid receptor induces schizophrenia-related behaviors in mice. Neuropsychopharmacology 36, 14891504. doi: 10.1038/npp.2011.34

O’Shea, M., McGregor, I. S., and Mallet, P. E. (2006). Repeated cannabinoid exposure during perinatal, adolescent or early adult ages produces 
similar longlasting deficits in object recognition and reduced social interaction in rats. J. Psychopharmacol. 20, 611-621. doi: 10.1177/02698 81106065188

O'Shea, M., Singh, M. E., McGregor, I. S., and Mallet, P. E. (2004). Chronic cannabinoid exposure produces lasting memory impairment and increased anxiety in adolescent but not adult rats. J. Psychopharmacol. 18, 502-508. doi: $10.1177 / 026988110401800407$

Pacher, P., Steffens, S., Haskó, G., Schindler, T. H., and Kunos, G. (2018). Cardiovascular effects of marijuana and synthetic cannabinoids: the good, the bad, and the ugly. Nat. Rev. Cardiol. 15, 151-166. doi: $10.1038 /$ nrcardio.2017.130

Pease-Raissi, S. E., and Chan, J. R. (2018). Micro(glial)-managing executive function: white matter inflammation drives catatonia. J. Clin. Invest. 128, 564-566. doi: 10.1172/JCI98761

Pertwee, R. G. (2008). The diverse CB1 and CB2 receptor pharmacology of three plant cannabinoids: delta9-tetrahydrocannabinol, cannabidiol and delta9tetrahydrocannabivarin. Br. J. Pharmacol. 153, 199-215. doi: 10.1038/sj.bjp. 0707442

Quinn, H. R., Matsumoto, I., Callaghan, P. D., Long, L. E., Arnold, J. C., Gunasekaran, N., et al. (2008). Adolescent rats find repeated Delta(9)THC less aversive than adult rats but display greater residual cognitive deficits and changes in hippocampal protein expression following exposure. Neuropsychopharmacology 33, 1113-1126. doi: 10.1038/sj. npp. 1301475

Raboune, S., Stuart, J. M., Leishman, E., Takacs, S. M., Rhodes, B., Basnet, A., et al. (2014). Novel endogenous $\mathrm{N}$-acyl amides activate TRPV1-4 receptors, BV-2 microglia, and are regulated in brain in an acute model of inflammation. Front Cell. Neurosci. 8:195. doi: 10.3389/fncel.2014.00195

Reisenberg, M., Singh, P. K., Williams, G., and Doherty, P. (2012). The diacylglycerol lipases: structure, regulation and roles in and beyond endocannabinoid signalling. Philos. Trans. R. Soc. Lond. B Biol. Sci. 367, 32643275. doi: $10.1098 /$ rstb.2011.0387

Renard, J., Krebs, M. O., Jay, T. M., and Le Pen, G. (2013). Long-term cognitive impairments induced by chronic cannabinoid exposure during adolescence in rats: a strain comparison. Psychopharmacology 225, 781-790. doi: 10.1007/ s00213-012-2865-z

Rimmerman, N., Bradshaw, H. B., Hughes, H. V., Chen, J. S., Hu, S. S., McHugh, D., et al. (2008). N-palmitoyl glycine, a novel endogenous lipid that acts as a modulator of calcium influx and nitric oxide production in sensory neurons. Mol. Pharmacol. 74, 213-224. doi: 10.1124/mol. 108.045997

Rimmerman, N., Bradshaw, H. B., Kozela, E., Levy, R., Juknat, A., and Vogel, Z. (2012). Compartmentalization of endocannabinoids into lipid rafts in a microglial cell line devoid of caveolin1. Br. J. Pharmacol. 165, 2436-2449. doi: 10.1111/j.1476-5381. 2011.01380.x

Rouzer, C. A., and Marnett, L. J. (2011). Endocannabinoid oxygenation by cyclooxygenases, lipoxygenases, and cytochromes P450: cross-talk between the eicosanoid and endocannabinoid signaling pathways. Chem. Rev. 111, 58995921. doi: $10.1021 / \mathrm{cr} 2002799$

Rubino, T., and Parolaro, D. (2014). Cannabis abuse in adolescence and the risk of psychosis: a brief review of the preclinical evidence. Prog. Neuropsychopharmacol. Biol. Psychiatry 52, 41-44. doi: 10.1016/j.pnpbp.2013. 07.020

Rubino, T., and Parolaro, D. (2015). The impact of exposure to cannabinoids in adolescence: insights from animal models. Biol. Psychiatry 79, 578-585. doi: 10.1016/j.biopsych.2015.07.024

Rubino, T., Prini, P., Piscitelli, F., Zamberletti, E., Trusel, M., Melis, M., et al. (2015). Adolescent exposure to THC in female rats disrupts developmental changes in the prefrontal cortex. Neurobiol. Dis. 73, 60-69. doi: 10.1016/j.nbd. 2014.09.015

Ryberg, E., Larsson, N., Sjogren, S., Hjorth, S., Hermansson, N. O., Leonova, J., et al. (2007). The orphan receptor GPR55 is a novel cannabinoid receptor. $\mathrm{Br}$. J. Pharmacol. 152, 1092-1101. doi: 10.1038/sj.bjp.0707460

Saghatelian, A., McKinney, M. K., Bandell, M., Patapoutian, A., and Cravatt, B. F. (2006). A FAAH-regulated class of N-acyl taurines that activates TRP ion channels. Biochemistry 45, 9007-9015. doi: 10.1021/ bi0608008
Samra, K., Boon, I. S., Packer, G., and Jacob, S. (2017). Lethal high: acute disseminated encephalomyelitis (ADEM) triggered by toxic effect of synthetic cannabinoid black mamba. BMJ Case Rep. 2017, bcr-2016-218431. doi: 10.1136/ bcr-2016-218431

Savinainen, J. R., Saario, S. M., and Laitinen, J. T. (2012). The serine hydrolases MAGL, ABHD6 and ABHD12 as guardians of 2-arachidonoylglycerol signalling through cannabinoid receptors. Acta Physiol. 204, 267-276. doi: 10. $1111 /$ j.1748-1716.2011.02280.x

Schneir, A. B., Cullen, J., and Ly, B. T. (2011). "Spice" girls: synthetic cannabinoid intoxication. J. Emerg. Med. 40, 296-299. doi: 10.1016/j.jemermed. 2010.10.014

Shoemaker, J. L., Joseph, B. K., Ruckle, M. B., Mayeux, P. R., and Prather, P. L. (2005). The endocannabinoid noladin ether acts as a full agonist at human CB2 cannabinoid receptors. J. Pharmacol. Exp. Ther. 314, 868-875. doi: 10.1124/jpet. 105.085282

Shonesy, B. C., Bluett, R. J., Ramikie, T. S., Báldi, R., Hermanson, D. J., Kingsley, P. J., et al. (2014). Genetic disruption of 2-arachidonoylglycerol synthesis reveals a key role for endocannabinoid signaling in anxiety modulation. Cell Rep. 9, 1644-1653. doi: 10.1016/j.celrep.2014.11.001

Showalter, V. M., Compton, D. R., Martin, B. R., and Abood, M. E. (1996). Evaluation of binding in a transfected cell line expressing a peripheral cannabinoid receptor (CB2): identification of cannabinoid receptor subtype selective ligands. J. Pharmacol. Exp. Ther. 278, 989-999.

Simon, G. M., and Cravatt, B. F. (2006). Endocannabinoid biosynthesis proceeding through glycerophospho- $\mathrm{N}$-acyl ethanolamine and a role for alpha/betahydrolase 4 in this pathway. J. Biol. Chem. 281, 26465-26472. doi: 10.1074/jbc. M604660200

Smoum, R., Bar, A., Tan, B., Milman, G., Attar-Namdar, M., Ofek, O., et al. (2010). Oleoyl serine, an endogenous $\mathrm{N}$-acyl amide, modulates bone remodeling and mass. Proc. Natl. Acad. Sci. U.S.A. 107, 17710-17715. doi: 10.1073/pnas. 0912479107

Stuart, J. M., Paris, J. J., Frye, C., and Bradshaw, H. B. (2013). Brain levels of prostaglandins, endocannabinoids, and related lipids are affected by mating strategies. Int. J. Endocrinol. 2013:436252. doi: 10.1155/2013 1436252

Sugiura, T., Kondo, S., Sukagawa, A., Nakane, S., Shinoda, A., Itoh, K., et al. (1995). 2-Arachidonoylglycerol: a possible endogenous cannabinoid receptor ligand in brain. Biochem. Biophys. Res. Commun. 215, 89-97. doi: 10.1006/bbrc. 1995.2437

Tan, B., Bradshaw, H. B., Rimmerman, N., Srinivasan, H., Yu, Y. W., Krey, J. F., et al. (2006). Targeted lipidomics: discovery of new fatty acyl amides. AAPS J. 8, E461-E465. doi: 10.1208/aapsj080354

Tanimura, A., Yamazaki, M., Hashimotodani, Y., Uchigashima, M., Kawata, S., Abe, M., et al. (2010). The endocannabinoid 2-arachidonoylglycerol produced by diacylglycerol lipase alpha mediates retrograde suppression of synaptic transmission. Neuron 65, 320-327. doi: 10.1016/j.neuron.2010.01.021

Thomas, B. F. (2017). Interactions of cannabinoids with biochemical substrates. Subst. Abuse 11:1178221817711418. doi: 10.1177/11782 21817711418

Tortoriello, G., Rhodes, B. P., Takacs, S. M., Stuart, J. M., Basnet, A., Raboune, S., et al. (2013). Targeted lipidomics in Drosophila melanogaster identifies novel 2-monoacylglycerols and N-acyl amides. PLoS One 8:e67865. doi: 10.1371/ journal.pone. 0067865

Tseng, A. H., and Craft, R. M. (2004). CB 1 receptor mediation of cannabinoid behavioral effects in male and female rats. Psychopharmacology 172, 25-30. doi: $10.1007 / \mathrm{s} 00213-003-1620-\mathrm{x}$

Uchiyama, N., Kikura-Hanajiri, R., Kawahara, N., and Goda, Y. (2009a). Identification of a cannabimimetic indole as a designer drug in a herbal product. Forensic Toxicol. 27, 61-66.

Uchiyama, N., Kikura-Hanajiri, R., Kawahara, N., Haishima, Y., and Goda, Y. (2009b). Identification of a cannabinoid analog as a new type of designer drug in a herbal product. Chem. Pharm. Bull. 57, 439-441.

Underwood, E. (2015). Alarm over synthetic cannabinoids. Science 347, 473-473. doi: $10.1126 /$ science.347.6221.473

van der Wel, T., Janssen, F. J., Baggelaar, M. P., Deng, H., den Dulk, H., Overkleeft, H. S., et al. (2015). A natural substrate-based fluorescence assay for inhibitor screening on diacylglycerol lipase $\alpha$. J. Lipid Res. 56, 927-935. doi: 10.1194/jlr. D056390 
Wilkerson, J. L., Donvito, G., Grim, T. W., Abdullah, R. A., Ogasawara, D., Cravatt, B. F., et al. (2017). Investigation of diacylglycerol lipase alpha inhibition in the mouse lipopolysaccharide inflammatory pain model. J. Pharmacol. Exp. Ther. 363, 394-401. doi: 10.1124/jpet.117. 243808

Wilson, R. I., and Nicoll, R. A. (2001). Endogenous cannabinoids mediate retrograde signalling at hippocampal synapses. Nature 410, 588-592. doi: 10 . 1038/35069076

Zamberletti, E., Prini, P., Speziali, S., Gabaglio, M., Solinas, M., Parolaro, D., et al. (2012). Gender-dependent behavioral and biochemical effects of adolescent delta-9-tetrahydrocannabinol in adult maternally deprived rats. Neuroscience 204, 245-257. doi: 10.1016/j.neuroscience. 2011.11.038

Zygmunt, P. M., Petersson, J., Andersson, D. A., Chuang, H., Sorgard, M., Di Marzo, V., et al. (1999). Vanilloid receptors on sensory nerves mediate the vasodilator action of anandamide. Nature 400, 452-457. doi: 10.1038/22761
Conflict of Interest Statement: The author, HB, of this manuscript is on the Advisory Board for Phytecs and consults on how endogenous cannabinoids function in the central nervous system. Phytecs had no financial contribution to the current work.

The remaining authors declare that the research was conducted in the absence of any commercial or financial relationships that could be construed as a potential conflict of interest.

Copyright (C) 2018 Leishman, Murphy, Murphy, Mackie and Bradshaw. This is an open-access article distributed under the terms of the Creative Commons Attribution License (CC BY). The use, distribution or reproduction in other forums is permitted, provided the original author(s) and the copyright owner(s) are credited and that the original publication in this journal is cited, in accordance with accepted academic practice. No use, distribution or reproduction is permitted which does not comply with these terms. 